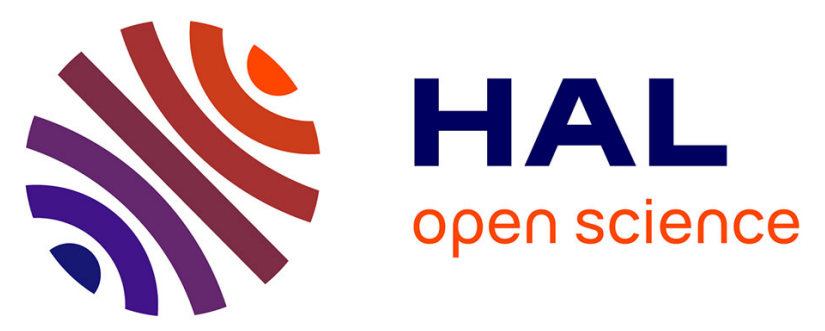

\title{
Lead sorption by biochar produced from digestates: Consequences of chemical modification and washing
}

Suchanya Wongrod, Stéphane Simon, Gilles Guibaud, Piet N.L. Lens, Yoan

Pechaud, David Huguenot, Eric D. van Hullebusch

\section{- To cite this version:}

Suchanya Wongrod, Stéphane Simon, Gilles Guibaud, Piet N.L. Lens, Yoan Pechaud, et al.. Lead sorption by biochar produced from digestates: Consequences of chemical modification and washing. Journal of Environmental Management, 2018, 219, pp.277-284. 10.1016/j.jenvman.2018.04.108 . hal02141756

\section{HAL Id: hal-02141756 \\ https://hal.science/hal-02141756}

Submitted on 28 May 2019

HAL is a multi-disciplinary open access archive for the deposit and dissemination of scientific research documents, whether they are published or not. The documents may come from teaching and research institutions in France or abroad, or from public or private research centers.
L'archive ouverte pluridisciplinaire $\mathbf{H A L}$, est destinée au dépôt et à la diffusion de documents scientifiques de niveau recherche, publiés ou non, émanant des établissements d'enseignement et de recherche français ou étrangers, des laboratoires publics ou privés. 


\title{
Lead sorption by biochar produced from digestates:
}

\section{Consequences of chemical modification and washing}

Suchanya Wongrod ${ }^{\mathrm{a}, \mathrm{b}, \mathrm{c}}$, Stéphane Simon ${ }^{\mathrm{c}}$, Gilles Guibaud ${ }^{\mathrm{c}, *}$, Piet N.L. Lens ${ }^{\mathrm{b}}$, Yoan Pechaud ${ }^{\mathrm{a}}$, David Huguenot ${ }^{\mathrm{a}}$, Eric D. van Hullebusch ${ }^{\mathrm{a}, \mathrm{b}}$

\footnotetext{
${ }^{a}$ Université Paris-Est, Laboratoire Géomatériaux et Environnement (EA 4508), UPEM, 77454, Marne-laVallée, France

${ }^{\mathrm{b}}$ IHE Delft Institute for Water Education, P.O. Box 3015, 2601 DA Delft, The Netherlands

${ }^{c}$ Université de Limoges, PEIRENE-Groupement de Recherche Eau Sol Environnement (EA 7500), Faculté des Sciences et Techniques, 123 avenue Albert Thomas, 87060 Limoges, France
}

*Corresponding author: gilles.guibaud@unilim.fr

\begin{abstract}
The main objectives of this work are to investigate the consequences of different chemical treatments (i.e. potassium hydroxide $(\mathrm{KOH})$ and hydrogen peroxide $\left(\mathrm{H}_{2} \mathrm{O}_{2}\right)$ ) and the effect of biochar washing on the $\mathrm{Pb}$ sorption capacity. Biochars derived from sewage sludge digestate and the organic fraction of municipal solid waste digestate were separately modified with 2 $\mathrm{M} \mathrm{KOH}$ or $10 \% \mathrm{H}_{2} \mathrm{O}_{2}$ followed by semi-continuous or continuous washing with ultrapure water using batch or a column reactor, respectively. The results showed that the $\mathrm{Pb}$ adsorption capacity could be enhanced by chemical treatment of sludge-based biochar. Indeed, for municipal solid waste biochar, the $\mathrm{Pb}$ maximum sorption capacity was improved from $73 \mathrm{mg} \mathrm{g}^{-1}$ for unmodified biochar to $90 \mathrm{mg} \mathrm{g}^{-1}$ and $106 \mathrm{mg} \mathrm{g}^{-1}$ after $\mathrm{H}_{2} \mathrm{O}_{2}$ and $\mathrm{KOH}$
\end{abstract}


treatment, respectively. In the case of sewage sludge biochar, it increased from $6.5 \mathrm{mg} \mathrm{g}^{-1}$ (unmodified biochar) to $25 \mathrm{mg} \mathrm{g}^{-1}$ for $\mathrm{H}_{2} \mathrm{O}_{2}$ treatment. The sorption capacity was not determined after $\mathrm{KOH}$ treatment, since the Langmuir model did not fit the experimental data. The study also highlights that insufficient washing after $\mathrm{KOH}$ treatment can strongly hinder $\mathrm{Pb}$ sorption due to the release of organic matter from the modified biochar. This organic matter may interact in solution with $\mathrm{Pb}$, resulting in an inhibition of its sorption onto the biochar surface. Continuous column-washing of modified biochars was able to correct this issue, highlighting the importance of implementing a proper treated biochar washing procedure.

Keywords biochar, digestate, sorption, organic sludge, lead 


\section{Introduction}

Metal pollution is of very high concerns for human health due to their persistence and toxicity in the environment even in low concentrations. Lead $(\mathrm{Pb})$ has been recognized as one of the most toxic metals in Europe (Tóth et al., 2016). Pb pollution often originates from smelters, mining, industrial discharges, car batteries and Pb-based piping for water supply. Discharge of untreated wastewater from the industry may cause an adverse effect to animals and humans. One study reported a case of severe $\mathrm{Pb}$ poisoning of children in Haina (Dominican Republic), attributed to a car battery recycling factory (Kaul et al., 1999). Many conventional treatment methods have been developed to decrease $\mathrm{Pb}$ levels in contaminated water, including chemical precipitation, coagulation, ion exchange and adsorption (Inyang et al., 2015).

Lead sorption by activated carbon (Cechinel et al., 2014), agricultural waste-derived biochars (e.g. pine wood or rice husk) (Liu \& Zhang, 2009), natural zeolite and kaolinite clay (Andrejkovicova et al., 2016; Jiang et al., 2009) have been reported. Recent studies show the potential application of biochar in metal-polluted water treatment due to its high specific surface area and surface properties, e.g. surface charge and hydrophobicity (Liu \& Zhang, 2009; Zielińska et al., 2015). Indeed, the solid organic by-product generated by anaerobic digestion of sludge from wastewater treatment plants has been considered as an alternative source of raw material to manufacture adsorbents (i.e. biochar) for metal removal (Zhang et al., 2013). Biochar is a black solid char derived from the pyrolysis of organic waste materials in a limiting oxygen environment (Inyang et al., 2015). Through the pyrolysis technology, it promotes the recycling of organic waste and supports the environmental sustainability for the community. Biochar has been widely used for many purposes in the environment, such as soil conditioner (Saifullah et al., 2018) or filtration medium in wastewater treatment (Mohan et al., 2014). However, there are only few studies on the use of organic by-product sludge 
biochar to remove metals from water. Biochar produced from organic digested sludge has been used for $\mathrm{As}(\mathrm{V}), \mathrm{Cd}(\mathrm{II}), \mathrm{Cr}(\mathrm{III}), \mathrm{Cu}(\mathrm{II})$ and $\mathrm{Ni}(\mathrm{II})$ removal from water (Inyang et al., 2012; Jin et al., 2014). A few studies have been dedicated to the Pb sorption by sludge biochars, which can be found in the literature (Table S1).

The main mechanisms involved in $\mathrm{Pb}$ sorption onto the biochar are cation exchange, surface complexation, surface precipitation and physical adsorption (Ho et al., 2017; Li et al., 2017). Among these mechanisms, cation exchange of $\mathrm{Pb}$ with $\mathrm{Ca}^{2+}$ and $\mathrm{Mg}^{2+}$ is the main contributor to $\mathrm{Pb}$ sorption by sludge-based biochar, accounting for $40-52 \%$. Exchanges can also occur to a lesser extend with $\mathrm{K}^{+}$and $\mathrm{Na}^{+}$(<8.5\%) ( $\mathrm{Li}$ et al., 2017), which is in a good agreement with the study of $\mathrm{Lu}$ et al. (2012). The surface complexation between $\mathrm{Pb}$ and surface functional groups of biochar (e.g. carboxyl and hydroxyl groups) also plays a major role, contributing for about $40 \%$ of $\mathrm{Pb}$ removal ( $\mathrm{Li}$ et al., 2017). Surface precipitation can also occur since sludge biochars generally contain high amounts of phosphate $\left(\mathrm{PO}_{4}{ }^{3-}\right)$ and carbonate $\left(\mathrm{CO}_{3}{ }^{2-}\right)$ on their surface. Finally, the high surface area of biochar may favor physical adsorption of $\mathrm{Pb}$ onto biochar active pore sites (Agrafioti et al., 2014). The relative importance of these sorption mechanisms depends on the biochar feedstock.

Compared to activated carbon, the sorption capacity for $\mathrm{Pb}$ by biochar is low and thus numerous modification methods have been applied to improve it. The common treatment methods of biochar are physical activation with steam and chemical treatment with acids, oxidizing agents and alkali solutions (Sizmur et al., 2017). The steam activation of biochar is usually performed at high temperature $\left(>800{ }^{\circ} \mathrm{C}\right)$, thus increasing the adsorbent cost which it is not feasible for large scale operation (Wang and Liu, 2018). The chemical modification of biochar is considered as an inexpensive technique since no heat is required during the operation. Treatment of biochar with $\mathrm{KOH}$ increases the surface hydroxyl groups and the basicity on the biochar surface (Fan et al., 2016; Li et al., 2014), dissolves ash and condenses 
organic matter (e.g. lignin and celluloses) in the biochar (Lin et al., 2012; Liou \& Wu, 2009; Liu et al., 2012). Modification of biochar with $\mathrm{H}_{2} \mathrm{O}_{2}$ was found to increase O-containing functional groups, particularly carboxyl groups, on the biochar surfaces (Rajapaksha et al., 2016). Such chemical modifications could induce a leaching of organic matter and mineral ash from biochar pore sites. Thus, after the treatment, several batch washing of the biochar with ultrapure water are required until the $\mathrm{pH}$ becomes stable or neutral (Huang et al., 2017; Regmi et al., 2012; Wu et al., 2017). Usually, batch washing of biochar is performed without any concerns on the release of organic or inorganic compounds (e.g. $\mathrm{PO}_{4}{ }^{3-}$ and $\left.\mathrm{CO}_{3}{ }^{2-}\right)$ from biochar. Since this can influence the sorption of metals by biochar, the effective elimination of these released compounds should be considered. Unfortunately, there is currently a lack of information on the effect of biochar washing on the elimination of the released compounds from biochar after chemical treatment.

This work aims to study the consequences of chemical treatments of biochar and subsequent washing conditions on the $\mathrm{Pb}$ sorption capacity. Two chemical reagents (i.e. $\mathrm{KOH}$ and $\mathrm{H}_{2} \mathrm{O}_{2}$ ) and two washing modes (semi-continuous batch washing as usually performed in the literature and continuous column washing) were applied to raw biochars from sewage sludge and the organic fraction of municipal solid waste. The consequences onto the $\mathrm{Pb}$ sorption were evaluated through adsorption kinetic and isotherm studies.

\section{Materials and methods}

\subsection{Feedstocks and biochar preparation}

Raw sewage sludge digestate (RSS) and raw organic fraction of municipal solid waste digestate (RMSW) were obtained separately from a wastewater treatment plant and from a solid waste treatment plant located in France. Biochar from RSS was industrially pyrolyzed at 
$350{ }^{\circ} \mathrm{C}$ for 15 min using the Biogreen ${ }^{\circledR}$ technology, while biochar from RMSW was produced at lab scale. Based on the study of Pituello et al. (2014), the RMSW was dried overnight at $65{ }^{\circ} \mathrm{C}$ to reduce the initial moisture content to less than $10 \%$. After that, it was crushed and sieved into a particle size of $2 \mathrm{~mm}$ to separate impurities such as plastic bags, needles and glasses. The RMSW-derived biochar was produced at $400{ }^{\circ} \mathrm{C}$ using porcelain crucibles with lid-cover (Haldenwanger $79 \mathrm{MF}$, Germany) in a muffle furnace (heating rate $15^{\circ} \mathrm{C} \min ^{-1}$ ) for $1 \mathrm{~h}$. The obtained materials were left to cool down at room temperature with the lids cover.

As recommended by Jin et al. (2014), Wu et al. (2017) and Xue et al. (2012), biochars were washed by semi-continuous means with ultrapure water for 3-4 times (i.e. $2 \mathrm{~g}$ of biochar per $200 \mathrm{~mL}$ of ultrapure water per washing) until a stable $\mathrm{pH}$ was obtained. The RSSderived biochar produced at $350{ }^{\circ} \mathrm{C}$ and the RMSW-derived biochar produced at $400{ }^{\circ} \mathrm{C}$ are named as $\mathrm{SS}^{\mathrm{sem}}$ and $\mathrm{MSW}^{\mathrm{sem}}$, respectively.

\subsection{Biochar chemical modification}

In this study, $\mathrm{KOH}$ and $\mathrm{H}_{2} \mathrm{O}_{2}$ were selected for the chemical modification of biochar due to the great enhancement of metal sorption (Rajapaksha et al., 2016). To prepare the modified biochar with $\mathrm{H}_{2} \mathrm{O}_{2}, 2 \mathrm{~g}$ of biochar was placed into $20 \mathrm{~mL}$ of a $10 \% \mathrm{H}_{2} \mathrm{O}_{2}$ solution and shaken at $25( \pm 2){ }^{\circ} \mathrm{C}$ for $2 \mathrm{~h}$ (modified from Xue et al., 2012). Biochar treated with $\mathrm{KOH}$ was prepared by mixing $2 \mathrm{~g}$ biochar with $100 \mathrm{~mL}$ of $2 \mathrm{M} \mathrm{KOH}$ solution and was shaken at 25 $( \pm 2){ }^{\circ} \mathrm{C}$ for $2 \mathrm{~h}$ (modified from Jin et al., 2014). The total mass of biochar used was around $10 \mathrm{~g}$ per each chemical treatment. After chemical modification, biochars were all semicontinuously washed with ultrapure water. Some biochars were submitted to a subsequent continuously washing to study the influence of the washing conditions. 
For the semi-continuous washing, the chemically modified biochar was washed in batch by stirring $2 \mathrm{~g}$ of biochar in $200 \mathrm{~mL}$ of ultrapure water at $20( \pm 2){ }^{\circ} \mathrm{C}$. The batch washing was repeated for 3-4 times until the pH became stable (Jin et al., 2014; Wu et al., 2017; Xue et al., 2012). For the continuous washing, a part of the semi-continuous washed biochar was subsequently washed by continuous circulation of ultrapure water in a glass column $(2.8 \mathrm{~cm}$ in diameter and $42.5 \mathrm{~cm}$ in height). A peristaltic pump (Ismatec Reglo Analog, Model No. ISM827, Ismatec SA Company, Switzerland) was used to maintain the up-flow velocity of $0.77( \pm 0.01) \mathrm{cm} \mathrm{min}^{-1}$. Glass beads $(2 \mathrm{~mm}$ size $)$ were used at the bottom of the column to generate the flow distribution. The column was flushed continuously for at least $70 \mathrm{~h}$ at $20( \pm 2)^{\circ} \mathrm{C}$ with a hydraulic retention time of $6 \mathrm{~h}$.

Once washed, the modified biochars were recovered using VWR filter papers, then dried in an oven at $50{ }^{\circ} \mathrm{C}$ overnight and further kept in a desiccator prior to use. The semicontinuously washed $\mathrm{H}_{2} \mathrm{O}_{2}$ and $\mathrm{KOH}$-treated biochars are labeled as $\mathrm{MSW}-\mathrm{H}_{2} \mathrm{O}_{2}{ }^{\text {sem }}$, MSW$\mathrm{KOH}^{\mathrm{sem}}, \mathrm{SS}-\mathrm{H}_{2} \mathrm{O}_{2}{ }^{\text {sem }}$ and SS- $\mathrm{KOH}^{\text {sem }}$ for RMSW and SS based biochar, respectively. The continuously washed $\mathrm{H}_{2} \mathrm{O}_{2}$ and $\mathrm{KOH}$-treated sewage sludge biochars are labeled as SS$\mathrm{H}_{2} \mathrm{O}_{2}{ }^{\text {con }}$ and SS- $\mathrm{KOH}^{\mathrm{con}}$, respectively.

\subsection{Biochar characterization}

The $\mathrm{pH}$ of the biochar was measured using a pH meter (LPH 330T, Tacussel, France). A suspension of $1 \mathrm{~g}$ of sample in $20 \mathrm{~mL}$ of deionized water was stirred continuously for 5 min and let to suspend for $15 \mathrm{~min}$.

To quantify the total content of metal(loid)s (i.e. $\mathrm{Al}, \mathrm{As}, \mathrm{Cd}, \mathrm{Cr}, \mathrm{Cu}, \mathrm{Ni}, \mathrm{Pb}, \mathrm{Mn}, \mathrm{Fe}$ and $\mathrm{Zn}$ ) and cationic macroelements (i.e. $\mathrm{Ca}, \mathrm{K}, \mathrm{Mg}$ and $\mathrm{Na}$ ) in biochar, an acid digestion was performed using $\mathrm{H}_{2} \mathrm{O}_{2}(30 \%$ w/w, Sigma-Aldrich) and concentrated $\mathrm{HCl}(37 \%$ w/w, Merck) and $\mathrm{HNO}_{3}(65 \%$ w/w, Merck) according to EPA Method 3050B (EPA, 1996). The 
digestion was carried out in a heating block at $95( \pm 5){ }^{\circ} \mathrm{C}$. After filtration with a Whatman grade 1 qualitative filter paper, trace elements were analyzed using inductively coupled plasma optical emission spectroscopy (ICP-OES) (Optima 8300, PerkinElmer, France).

An X-ray powder diffractometer (AXS D8, Bruker, Germany) was used to identify the crystalline structures of the biochars. Fourier transform infrared (FTIR) spectroscopy (IRAffinity-1, Shimadzu, Japan) was used to identify surface functional groups of biochar with a deuterated-triglycine sulfate (DTGS) detector. The details of the sample preparation for XRD and FTIR analysis are described in the Supplementary Information. BrunauerEmmett-Teller (BET) specific surface area of chemically-modified biochar samples were determined using the $\mathrm{N}_{2}$ adsorption method at $77 \mathrm{~K}$ (3Flex, Micromeritics, USA). Before BET analysis, the biochar samples were dried at $105^{\circ} \mathrm{C}$ for $5 \mathrm{~h}$.

\subsection{Characterization of solution after column washing of biochar}

During continuous washing of $\mathrm{SS}-\mathrm{KOH}^{\mathrm{sem}}$ and $\mathrm{SS}-\mathrm{H}_{2} \mathrm{O}_{2}{ }^{\mathrm{sem}}$, liquid samples were collected at the outlet of the column over time to measure pH (LPH 330T, Tacussel, France), conductivity (CDM 210 conductivity-meter, Radiometer, Copenhagen, Denmark), dissolved organic carbon (DOC), $\mathrm{PO}_{4}{ }^{3-}, \mathrm{CO}_{3}{ }^{2-}$ and bicarbonate $\left(\mathrm{HCO}_{3}^{-}\right)$. Dissolved organic carbon was determined using a TOC Analyzer (multi N/C ${ }^{\circledR} 2100 S$, Analytikjena, Germany) according to the standard method from Afnor (Afnor, 1997a). A colorimetric method (Afnor, 1997b) was used to measure $\mathrm{PO}_{4}{ }^{3-}$ with a spectrophotometer (DR1900, Hach, France) at $\lambda$ $700 \mathrm{~nm}$. For $\mathrm{CO}_{3}{ }^{2-}$ and $\mathrm{HCO}_{3}{ }^{-}$, they were analyzed by a titrimetric method (Afnor, 1996) using $10^{-3} \mathrm{M} \mathrm{HCl}$ as a titrant and phenolphthalein and mixed bromocresol green-methyl red as indicators. Microwave Plasma Atomic Emission Spectroscopy (MP-AES) (Agilent 4100, Agilent Technologies Inc., USA) was used to analyze the released concentration of Ca and $\mathrm{Mg}$ at $\lambda 422.673 \mathrm{~nm}$ and $\lambda 285.213 \mathrm{~nm}$, respectively. 


\subsection{Sorption experiments}

A stock solution of $1000 \mathrm{mg} \mathrm{L}{ }^{-1} \mathrm{~Pb}(\mathrm{II})$ was prepared from $\mathrm{Pb}\left(\mathrm{NO}_{3}\right)_{2}$. The solution was diluted in the range from 10 to $1000 \mathrm{mg} \mathrm{L}^{-1}$ and the initial solution $\mathrm{pH}$ was adjusted to $5.0( \pm 0.2)$ by using $0.1 \mathrm{M} \mathrm{HNO}_{3}$ or $0.1 \mathrm{M} \mathrm{NaOH}$. For all sorption experiments, $100 \mathrm{mg}$ biochar was added to $25 \mathrm{~mL}$ of $\mathrm{Pb}$ solution and shaken at $20( \pm 2){ }^{\circ} \mathrm{C}$ using an orbital shaker (KS 501 digital, IKA ${ }^{\mathrm{TM}}$, USA) at $180 \mathrm{rpm}$. All experiments were conducted in triplicate and the average values are reported. Additional analyses were performed when variations over $10 \%$ were observed. Samples were filtered through Whatman polyethersulfone syringe filters $(0.2 \mu \mathrm{m})$ and analyzed by MP-AES (Agilent 4100, Agilent Technologies Inc., USA) at $\lambda$ $405.781 \mathrm{~nm}$ to quantify the remaining $\mathrm{Pb}$ concentration in solution.

Adsorption kinetic tests for $\mathrm{Pb}$ sorption onto raw and chemically-modified biochars from semi-continuous washing conditions (i.e. $\mathrm{MSW}^{\mathrm{sem}}, \mathrm{MSW}-\mathrm{H}_{2} \mathrm{O}_{2}{ }^{\mathrm{sem}}, \mathrm{MSW}-\mathrm{KOH}^{\mathrm{sem}}$, $\mathrm{SS}^{\mathrm{sem}}, \mathrm{SS}-\mathrm{H}_{2} \mathrm{O}_{2}{ }^{\mathrm{sem}}$ and SS-KOH${ }^{\mathrm{sem}}$ ) were performed to determine the time required to reach sorption equilibrium and the sorption kinetic constants using pseudo-first-order (PFO) and pseudo-second-order (PSO) models (kinetic equations are presented in Supplementary Information). These experiments were carried out with $100 \mathrm{mg} \mathrm{L}^{-1} \mathrm{~Pb}$ initial concentration, samples being collected after $10 \mathrm{~min}, 20 \mathrm{~min}, 30 \mathrm{~min}, 1 \mathrm{~h}, 2 \mathrm{~h}, 5 \mathrm{~h}, 7 \mathrm{~h}$ and $24 \mathrm{~h}$ of stirring.

Adsorption isotherms were performed with initial $\mathrm{Pb}$ concentrations between 10 and $1000 \mathrm{mg} \mathrm{L}^{-1}$. Two common adsorption isotherm models (Langmuir and Freundlich) were used to fit the experimental data. The details of these adsorption isotherm equations are provided in the Supplementary Information. 


\section{Results and discussion}

\subsection{Characterization of raw and chemically modified biochars}

The $\mathrm{pH}$ of suspensions of the raw and modified biochars is given in Table 1. A higher $\mathrm{pH}$ of the biochar compared to the raw feedstock was observed on both the organic fraction of municipal solid waste and sewage sludge digestate samples. The $\mathrm{pH}$ of $\mathrm{MSW}^{\mathrm{sem}}$ and $\mathrm{SS}^{\mathrm{sem}}$ was 8.9 and 6.5, respectively. This can be due to the presence of alkali compound (i.e. calcite) in the organic fraction of municipal solid waste biochar, while this component was not detected in sewage sludge digestate derived biochars (Fig. 1S). Chemical modification with $\mathrm{KOH}$ induced a significant shift to higher $\mathrm{pH}$ values, while a marginal $\mathrm{pH}$ variation was observed after $\mathrm{H}_{2} \mathrm{O}_{2}$ treatment (Table 2).

Table 1 shows the content of $\mathrm{Ca}, \mathrm{Mg}, \mathrm{Na}$ and $\mathrm{K}$ contained in the raw organic digestates (i.e. RMSW and RSS) and the derived biochars (i.e. $\mathrm{MSW}^{\mathrm{sem}}$ and $\mathrm{SS}^{\mathrm{sem}}$ ). It was noticed that higher cationic macroelements were found in $\mathrm{MSW}^{\mathrm{sem}}$ compared to $\mathrm{SS}^{\mathrm{sem}}$, particularly for $\mathrm{Ca}$ which was almost 4-fold higher in the former than in the latter (Table 1). In addition, the chemical characteristics such as ash and metal(loid) composition of RMSW, $\mathrm{MSW}^{\mathrm{sem}}$, RSS and $\mathrm{SS}^{\mathrm{sem}}$ are reported in Table S2. The XRD characterization demonstrates kaolinite, quartz and calcite were present in the biochars (Fig. S1). The presence of these mineral phases on the biochar surface could facilitate the sorption of metals (Al-Degs et al., 2006; Jiang et al., 2009). Additionally, biochar displays the presence of Al, Fe and Mn (Table 1) that could be partially in metal oxide form, i.e. $\mathrm{Al}_{2} \mathrm{O}_{3}, \mathrm{Fe}_{2} \mathrm{O}_{3}$ and $\mathrm{MnO}$. Thus, this could also promote interaction between the metal ions and biochar (Agrafioti et al., 2014; Wang et al., 2015).

FTIR spectra of $\mathrm{MSW}^{\mathrm{sem}}$ and $\mathrm{SS}^{\mathrm{sem}}$ show variations of the surface functional groups according to different biochar types (Fig. S2(a)). After alkali modification, stronger absorbance peaks corresponding to vibration of $\mathrm{O}-\mathrm{H}$ functional groups $\left(3425 \mathrm{~cm}^{-1}\right),-\mathrm{CH}_{3}$ 
stretching of long chain aliphatic groups $\left(2924 \mathrm{~cm}^{-1}\right)$ and vibration of the $\mathrm{C}-\mathrm{C}$ skeleton and C-O stretching $\left(1033 \mathrm{~cm}^{-1}\right.$ ) were found, especially on SS-KOH${ }^{\text {sem }}$ (Fig. S2(b)). Similar observations were reported by Petrovic et al. (2016) after alkali treatment of biochars. In addition, the FTIR spectra became more intense after $\mathrm{H}_{2} \mathrm{O}_{2}$ modification, particularly at 1640 $\mathrm{cm}^{-1}$ which is assigned to the vibrations of $\mathrm{C}=\mathrm{O}$ bands (ester) (Fig. S2(b)). Such surface functional groups can take part in the sorption mechanisms for metals (Chen et al., 2011; Pituello et al., 2014).

From Table 2, the BET specific surface areas of $\mathrm{SS}-\mathrm{H}_{2} \mathrm{O}_{2}{ }^{\mathrm{sem}}$ and $\mathrm{SS}-\mathrm{KOH}^{\mathrm{sem}}$ were 3.7 and $3.0 \mathrm{~m}^{2} \mathrm{~g}^{-1}$, respectively. These values increased after continuous washing with ultrapure water, probably due to the elimination of the ash content or organic matter from biochar pore sites.

\subsection{Effect of biochar washing after chemical modification}

After several batch-washings (semi-continuous mode) of $\mathrm{KOH}$ and $\mathrm{H}_{2} \mathrm{O}_{2}$-treated sewage sludge biochar, a subsequent column washing (continuous mode) was performed to highlight possible releases of organic or inorganic compounds from the biochar.

Fig. 1(a) and 1(b) represent the evolution of $\mathrm{pH}$ and conductivity of SS- $\mathrm{KOH}^{\mathrm{sem}}$ and SS- $\mathrm{H}_{2} \mathrm{O}_{2}{ }^{\text {sem }}$, respectively, along the column washing time. During the initial stage of washing $(0-5 \mathrm{~h})$, increases in $\mathrm{pH}$ were noticed for both $\mathrm{KOH}$ and $\mathrm{H}_{2} \mathrm{O}_{2}$-treated sewage sludge biochar. However, after $23 \mathrm{~h}$, the $\mathrm{pH}$ of SS-KOH${ }^{\text {sem }}$ started to decrease steadily before it became stable at $\mathrm{pH} 8.4$ (after $64 \mathrm{~h})$. The $\mathrm{pH}$ values remained almost unchanged at $6.5( \pm 0.1)$ for $\mathrm{SS}-\mathrm{H}_{2} \mathrm{O}_{2}{ }^{\text {sem }}$ beyond $23 \mathrm{~h}$. On the other hand, decreasing trends of conductivities throughout the manipulation were observed on both chemically-modified biochars (Fig. 1 (a, b)). The values dramatically dropped from $309-391 \mu \mathrm{S} \mathrm{cm}^{-1}$ (at the beginning) to $4-6 \mu \mathrm{S}$ 
$\mathrm{cm}^{-1}$ (at the end of operation), which was comparable to the conductivity of ultrapure water from the inlet flow $\left(\sim 3 \mu \mathrm{S} \mathrm{cm}{ }^{-1}\right)$.

Fig. 1(c) and 1(d) show the changes of phosphate, inorganic carbon and dissolved organic matter released from $\mathrm{SS}-\mathrm{KOH}^{\mathrm{sem}}$ and $\mathrm{SS}-\mathrm{H}_{2} \mathrm{O}_{2}{ }^{\mathrm{sem}}$, respectively, during column washing. The reduction of the $\mathrm{PO}_{4}{ }^{3-}, \mathrm{CO}_{3}{ }^{2-}, \mathrm{HCO}_{3}{ }^{-}$and DOC concentrations occurred continuously throughout the period of biochar washing (Fig. 1 (c, d)). Such evolutions are consistent with the conductivity trends (Fig. 1(a, b, c, d)). For instance, the high release of $\mathrm{PO}_{4}{ }^{3-}\left(55 \mathrm{mg} \mathrm{L}^{-1}\right), \mathrm{CO}_{3}{ }^{2-}\left(99 \mathrm{mg} \mathrm{L}^{-1}\right)$ and $\mathrm{HCO}_{3}^{-}\left(1418 \mathrm{mg} \mathrm{L}^{-1}\right)$ from KOH-treated biochar was related to the high conductivity $\left(391 \mu \mathrm{S} \mathrm{cm}^{-1}\right)$ (Fig. 1(a, c)) at the initial washing stage. Declining trends of the released compounds were observed along the lower conductivity level (Fig. 1(a, c)). Similarly, $\mathrm{SS}-\mathrm{H}_{2} \mathrm{O}_{2}{ }^{\text {sem }}$ showed the same behavior as SS$\mathrm{KOH}^{\text {sem }}$, but with much lower $\mathrm{PO}_{4}{ }^{3-}, \mathrm{CO}_{3}{ }^{2-}, \mathrm{HCO}_{3}{ }^{-}$and DOC concentrations (Fig. 1 (b, d)). By comparing $\mathrm{KOH}$ and $\mathrm{H}_{2} \mathrm{O}_{2}$ treatment, it appears that after $\mathrm{KOH}$ treatment the biochar released more organic compounds, $\mathrm{PO}_{4}{ }^{3-}$ and $\mathrm{CO}_{3}{ }^{2-} / \mathrm{HCO}_{3}{ }^{-}$compared to the $\mathrm{H}_{2} \mathrm{O}_{2}$ treatment. The DOC released was about 10-fold higher for SS- $\mathrm{KOH}^{\text {sem }}$ than for $\mathrm{SS}-\mathrm{H}_{2} \mathrm{O}_{2}{ }^{\text {sem }}$ (at $1 \mathrm{~h})$ (Fig. 1(c, d)). This is likely due to the property of KOH to modify the biochar surface. A similar behavior could be observed on the FTIR spectra, with a significant increase of transmittance for SS biochar treated with $\mathrm{KOH}$ (Fig. S2(b, c)).

These results clearly illustrate that a semi-continuous washing of chemically-treated biochar up to a stable $\mathrm{pH}$ was not sufficient to prevent the release of organic matter and ions. Indeed, in the batch reactor an equilibrium of released elements was achieved and the $\mathrm{pH}$ is usually used as an indicator for biochar washing (Huang et al., 2017; Regmi et al., 2012; Wu et al., 2017). However, to directly control the release of ions such as $\mathrm{PO}_{4}{ }^{3-}$ and $\mathrm{HCO}_{3}{ }^{-} / \mathrm{CO}_{3}{ }^{2-}$ from the biochar, conductivity is proposed as a more accurate parameter 
rather than the $\mathrm{pH}$. Therefore, a continuous washing with conductivity monitoring is recommended.

\subsection{Adsorption kinetics}

Fig. 2 shows the effect of contact time on the $\mathrm{Pb}$ removal capacity of $\mathrm{MSW}^{\mathrm{sem}}$, MSW$\mathrm{H}_{2} \mathrm{O}_{2}{ }^{\text {sem }}, \mathrm{MSW}-\mathrm{KOH}^{\mathrm{sem}}, \mathrm{SS}^{\mathrm{sem}}, \mathrm{SS}-\mathrm{H}_{2} \mathrm{O}_{2}{ }^{\text {sem }}$ and $\mathrm{SS}-\mathrm{KOH}^{\mathrm{sem}}$. The time required to reach the equilibrium state was different for each biochar type (Fig. 2). For sewage sludge based biochars, the equilibrium time was achieved after $5 \mathrm{~h}$ for raw $\mathrm{SS}^{\mathrm{sem}}, 7 \mathrm{~h}$ for $\mathrm{SS}-\mathrm{H}_{2} \mathrm{O}_{2}{ }^{\mathrm{sem}}$ and 2 h for SS-KOH ${ }^{\text {sem }}$, while MSW-based biochars showed faster kinetics compared to SS biochars in which the equilibrium time was reached within $5 \mathrm{~h}$ for $\mathrm{MSW}^{\mathrm{sem}}, 2 \mathrm{~h}$ for MSW$\mathrm{KOH}^{\mathrm{sem}}$ and $1 \mathrm{~h}$ for $\mathrm{MSW}-\mathrm{H}_{2} \mathrm{O}_{2}{ }^{\mathrm{sem}}$.

The data of the kinetic experiments were fitted using pseudo-first-order and pseudosecond-order equations. The corresponding kinetic parameters are given in Table S3. The pseudo-second order kinetic model was the most suitable to fit the experimental data for all biochars (Table S3). Considering the parameter $k_{2}$, it could be concluded that $\mathrm{MSW}-\mathrm{H}_{2} \mathrm{O}_{2}{ }^{\mathrm{sem}}$ exhibited the fastest kinetic rate followed by MSW-KOH ${ }^{\mathrm{sem}}, \mathrm{SS}-\mathrm{KOH}^{\mathrm{sem}}, \mathrm{MSW}^{\mathrm{sem}}, \mathrm{SS}^{\mathrm{sem}}$ and SS- $\mathrm{H}_{2} \mathrm{O}_{2}{ }^{\text {sem }}$ (Table S3). In addition, the equilibrium adsorption capacities determined by the second order model $\left(Q_{e}\right)$ were in agreement with the experimental ones $\left(Q_{e, \exp }\right)$ (Table S3).

Comparison of the different chemical modifications for biochar indicated that the alkali treatment $(\mathrm{KOH})$ could induce a faster $\mathrm{Pb}$ removal rate, especially for the organic fraction of municipal solid waste (MSW) biochar. This was supported by a previous study from Regmi et al. (2012) on a switchgrass biochar treated with alkali reagent. In contrast, biochar modified with an oxidizing agent $\left(\mathrm{H}_{2} \mathrm{O}_{2}\right)$ may not always increase the kinetic rate for $\mathrm{Pb}$ sorption. In this case, $\mathrm{SS}-\mathrm{H}_{2} \mathrm{O}_{2}{ }^{\mathrm{sem}}$ reached equilibrium slightly slower than $\mathrm{SS}^{\mathrm{sem}}$. 
Different kinetic rates for $\mathrm{Pb}$ adsorption were observed when comparing $\mathrm{SS}^{\mathrm{sem}}$ and $\mathrm{MSW}^{\text {sem }}$, the former requiring a longer time to reach sorption equilibrium. This was mainly due to differences in biochar properties resulting from the different origin of these biochars. FTIR spectra show stronger peaks of $\mathrm{O}-$ containing functional groups in $\mathrm{MSW}^{\mathrm{sem}}$ compared to $\mathrm{SS}^{\mathrm{sem}}$ especially at $1033 \mathrm{~cm}^{-1}$ (Fig. S2(a)), which could induce a faster kinetic rate for metals (Bogusz et al., 2017). In addition, $\mathrm{MSW}^{\mathrm{sem}}$ biochar contained calcite on its surface (Fig. S1(a)) and had higher cationic macroelements (i.e. $\mathrm{Ca}, \mathrm{K}, \mathrm{Mg}$ and $\mathrm{Na}$ ) content than $\mathrm{SS}^{\mathrm{sem}}$ biochar (Table 1) which could promote cationic metal (i.e. $\mathrm{Pb}$ ) binding onto $\mathrm{MSW}^{\text {sem }}$ biochar. This is consistent with the study of Zhang et al. (2017) on the use of celery biochars with high amounts of alkaline minerals for cationic metal removal from aqueous solutions. However, the physical properties of biochar like porosity and specific surface area should be also considered as they play a role during the adsorption process.

\subsection{Adsorption isotherms}

Fig. 3(a) and 3(b) show the adsorption isotherms for $\mathrm{Pb}$ by semi-continuous washed $\mathrm{SS}^{\mathrm{sem}}, \mathrm{SS}_{-} \mathrm{H}_{2} \mathrm{O}_{2}{ }^{\mathrm{sem}}, \mathrm{SS}-\mathrm{KOH}^{\mathrm{sem}}$ and by $\mathrm{MSW}^{\mathrm{sem}}, \mathrm{MSW}^{-\mathrm{H}_{2} \mathrm{O}_{2}}{ }^{\mathrm{sem}}$ and $\mathrm{MSW}-\mathrm{KOH}^{\mathrm{sem}}$, respectively. Table 3 presents the fitting parameters of the Langmuir and Freundlich isotherm models. All experimental data could be well-described by the Langmuir adsorption isotherms model $\left(R^{2}>0.98\right)$, except for SS-KOH ${ }^{\text {sem }}$.

The results from Fig. 3(a) demonstrate that chemical treatment of biochar could enhance the $\mathrm{Pb}$ sorption capacity from $6.5 \mathrm{mg} \mathrm{g}^{-1}$ on $\mathrm{SS}^{\mathrm{sem}}$ to $25.1 \mathrm{mg} \mathrm{g}^{-1}$ on $\mathrm{SS}_{-} \mathrm{H}_{2} \mathrm{O}_{2}{ }^{\text {sem }}$. However, it was completely different for SS-KOH ${ }^{\text {sem }}$ due to unexpected low $\mathrm{Pb}$ adsorption capacities at low equilibrium $\mathrm{Pb}$ concentration $\left(0-50 \mathrm{mg} \mathrm{L}^{-1}\right)$. As a result, the Langmuir model failed to describe the behavior of this sorption curve. One hypothesis is that a large amount of organic matter released from SS-KOH ${ }^{\text {sem }}$ (Fig. 1(c)) inhibits the Pb sorption onto 
the biochar by forming soluble $\mathrm{Pb}$-ligand complexes, resulting in lower $Q_{e}$ values at the low Ce range (0-50 $\left.\mathrm{mg} \mathrm{L}^{-1}\right)$.

Fig. 3(b) shows that the $\mathrm{Pb}$ sorption capability was improved by $\mathrm{KOH}$ and $\mathrm{H}_{2} \mathrm{O}_{2}$ treatment of MSW biochar. It increased from $72.9 \mathrm{mg} \mathrm{g}^{-1}$ for $\mathrm{MSW}^{\mathrm{sem}}$ to $90.0 \mathrm{mg} \mathrm{g}^{-1}$ and $106.3 \mathrm{mg} \mathrm{g}^{-1}$ for MSW- $\mathrm{H}_{2} \mathrm{O}_{2}{ }^{\text {sem }}$ and MSW-KOH ${ }^{\text {sem }}$, respectively. This implies that chemical treatment could be effectively used to promote $\mathrm{Pb}$ sorption onto the organic fraction of municipal solid waste-based biochar.

Fig. 4(a) shows the $\mathrm{Pb}$ adsorption isotherms on sewage sludge digestate-based biochars fitted with the Langmuir model (except $\mathrm{KOH}^{\mathrm{sem}}$ due to non-fitting). Fig. 4(b) and 4(c) compare the adsorption isotherms obtained for two different washing systems: batch semi-continuous versus batch followed by column continuous washing. From Fig. 4(b), a significant enhancement of $\mathrm{Pb}$ sorption by $\mathrm{KOH}^{\text {con }}$ (continuous washed) was observed compared to $\mathrm{KOH}^{\text {sem }}$ (semi-continuous washed) particularly at low $C_{e}\left(0-50 \mathrm{mg} \mathrm{L}^{-1}\right)$, highlighting the importance of biochar washing after chemical treatment. These results are consistent with the hypothesis of $\mathrm{Pb}$ sorption inhibition due to the formation of soluble complexes with organic matter released by the biochar. Such compounds were removed during the subsequent column washing, leading to a higher sorption capacity for $\mathrm{KOH}^{\mathrm{con}}$ compared to $\mathrm{KOH}^{\text {sem }}$, especially at low $\mathrm{Pb}$ equilibrium concentrations. In addition, the Langmuir adsorption model was then able to fit with experimental data of $\mathrm{KOH}^{\text {con }}$ (Table 3). However, no significant differences in $\mathrm{Pb}$ sorption capacities between $\mathrm{KOH}^{\text {sem }}$ and $\mathrm{KOH}^{\text {con }}$ were observed at higher $C_{e}\left(400-1000 \mathrm{mg} \mathrm{L}^{-1}\right)$ (Fig. 4(a)). This implies that the presence of organic matter in aqueous solutions significantly affects the $\mathrm{Pb}$ sorption onto biochar only at low $\mathrm{Pb}$ ion concentrations, especially $<50 \mathrm{mg} \mathrm{L}^{-1}$.

In contrast, similar adsorption capacities for $\mathrm{Pb}$ by both $\mathrm{H}_{2} \mathrm{O}_{2}{ }^{\text {sem }}$ and $\mathrm{H}_{2} \mathrm{O}_{2}{ }^{\text {con }}$ were achieved, even at low $\mathrm{Pb}$ equilibrium concentrations $\left(0-30 \mathrm{mg} \mathrm{L}^{-1}\right.$, Fig. 4(c)). This is 
because $\mathrm{H}_{2} \mathrm{O}_{2}$ treatment induced a small release of inorganic and organic matter from the modified biochar. As a result, batch washing was sufficient and no improvement was obtained with the subsequent column washing.

Fig. 4(d) and 4(e) compare the adsorption isotherms at low $C_{e}$ for $\mathrm{Pb}$ by $\mathrm{H}_{2} \mathrm{O}_{2}$ and $\mathrm{KOH}$ treated sewage sludge biochars on semi-continuous washing and continuous washing, respectively. The conclusions totally differ according to the washing procedure: the semicontinuous washing indicates that sorption is more important after $\mathrm{H}_{2} \mathrm{O}_{2}$ (Fig. 4(d)), whereas the continuous washing leads to the opposite conclusion (Fig. 4(e)). This is the consequence of the uncompleted efficiency of batch washing to remove the released compounds for biochar after $\mathrm{KOH}$ treatment.

Considering the maximal sorption capacity $\left(Q_{m}\right)$ of each biochar (Table 3 ), chemical treatments of biochar with $\mathrm{KOH}$ and $\mathrm{H}_{2} \mathrm{O}_{2}$ show an improved $\mathrm{Pb}$ sorption capacity, particularly on sewage sludge digestate biochar. Results show an enhanced $Q_{m}$ for $\mathrm{Pb}$ by almost 2 -fold for $\mathrm{SS}-\mathrm{H}_{2} \mathrm{O}_{2}{ }^{\text {con }}$ and by $12-$ fold for $\mathrm{SS}-\mathrm{KOH}^{\text {con }}$ with respect to the unmodified SS biochar. The use of KOH for chemical treatment thus appears more efficient than $\mathrm{H}_{2} \mathrm{O}_{2}$. However, a proper biochar washing procedure after chemical treatment is highly required to prevent the altered isotherm shape.

\subsection{Possible Pb sorption mechanisms}

Previous studies have illustrated the correlation of sorption for $\mathrm{Cu}^{2+}, \mathrm{Cd}^{2+}$ and $\mathrm{Pb}^{2+}$ with the oxygen-contained functional groups obtained from FTIR analysis (Petrovic et al., 2016; Regmi et al., 2012). The interactions between $\mathrm{Pb}$ and available surface functional groups on biochar can occur through surface complexation. In addition, possible cation exchange may take place. This is consistent with the observed release of $\mathrm{Ca}^{2+}$ and $\mathrm{Mg}^{2+}$ in solution after $\mathrm{Pb}$ sorption (Fig. 5). 
Fig. 5(a) compares the cations $\left(\mathrm{Ca}^{2+}\right.$ and $\left.\mathrm{Mg}^{2+}\right)$ released by $\mathrm{KOH}$-modified sewage sludge biochars from semi-continuous and continuous washing. The results show that the concentration of $\mathrm{Ca}^{2+}$ and $\mathrm{Mg}^{2+}$ released from SS- $\mathrm{KOH}^{\mathrm{sem}}$ was relatively low $\left(<3 \mathrm{mg} \mathrm{L}^{-1}\right)$ at initial $\mathrm{Pb}$ concentrations between $0-203 \mathrm{mg} \mathrm{L}^{-1}$. This was in correlation to a low sorption capacity for $\mathrm{Pb}$ by SS-KOH${ }^{\text {sem }}$ (see section 3.4). In contrast, a huge release of $\mathrm{Ca}^{2+}$ and $\mathrm{Mg}^{2+}$ by SS-KOH${ }^{\text {con }}$ was observed at adsorption equilibrium (Fig. 5(a)). The released $\mathrm{Ca}^{2+}$ and $\mathrm{Mg}^{2+}$ from this biochar was related to the amount of $\mathrm{Pb}$ adsorbed onto the biochar surface (on molecular mass basis) (Fig. 5(b)). These findings are in accordance with previous studies of biochars produced from grape pomace and water hyacinth for $\mathrm{Pb}$ and $\mathrm{Cd}$ removal, respectively (Petrovic et al., 2016; Zhang et al., 2015).

Moreover, the characterization of biochar shows the presence of a mineral phase that could also be involved in $\mathrm{Pb}$ sorption (Fig. S1). Nevertheless, previous links between the release of cations from biochar and the $\mathrm{Pb}$ sorption capacity show that sorption of $\mathrm{Pb}$ by the mineral phase in the biochar is not the main mechanism involved in sorption. In addition, $\mathrm{Pb}$ precipitation onto sludge biochar may contribute to the sorption mechanism. The results from the simulation shows that at initial $\mathrm{Pb}$ concentrations of 10 and $970 \mathrm{mg} \mathrm{L}^{-1}$ (Fig. S3), $\mathrm{Pb}$ precipitation onto biochar will likely occur when the final $\mathrm{pH}$ values are above 6.0 and above 5.0, respectively. Since the final $\mathrm{pH}$ in the solutions of both $\mathrm{SS}-\mathrm{KOH}^{\mathrm{sem}}$ and $\mathrm{MSW}-\mathrm{KOH}^{\mathrm{sem}}$ were above these values, $\mathrm{Pb}$ precipitation partly occurred on both biochar types during the sorption experiments.

\subsection{Practical implications}

The conversion of organic digested sludge obtained from wastewater treatment plants through pyrolysis is considered as a promising approach for sludge management. This corresponds to a huge reduction of the sludge quantity as well as a decrease of metal mobility 
in the sludge. It also promotes the environmental sustainability strategy due to recycling of the organic wastes and adding more value to the obtained products (i.e. biochar).

Chemical modification of biochar has been suggested as an economical technique to improve the sorption performance for $\mathrm{Pb}$. From this study, treatment of biochar with chemical reagents affected the sorption kinetics for $\mathrm{Pb}$. In this case, $\mathrm{KOH}$ could induce faster $\mathrm{Pb}$ removal rates compared to the unmodified biochars, while it was not systematic for biochars treated with $\mathrm{H}_{2} \mathrm{O}_{2}$. Furthermore, the chemically-modified biochars reveal a significant $\mathrm{Pb}$ sorption enhancement, but with a caution on proper-washed biochar especially with $\mathrm{KOH}$ treatment. Indeed, we observed that this treatment led to an inhibition of $\mathrm{Pb}$ sorption at low $\mathrm{Pb}$ initial concentration linked to the release of complexing compounds (e.g. phosphate, (bi)carbonate and organic matter). Thus, a sufficient biochar washing is required to remove these compounds prior to practical applications to ensure an improvement of the $\mathrm{Pb}$ sorption features and avoid the contamination of water bodies by the released products. Future research on the effect of biochar washing after chemical treatment is required to better understand the role of released organic compounds and other alkali anion ions on $\mathrm{Pb}$ sorption by sludge-based biochar.

\section{Conclusions}

This study demonstrated the capability of raw digested sludge biochars and chemically-modified biochars in $\mathrm{Pb}$ removal from water through adsorption kinetic and isotherm studies. Lead sorption data could be well-described by the Langmuir isotherm model and followed the pseudo-second-order kinetic model. The $\mathrm{KOH}$ treatment was found more efficient than the $\mathrm{H}_{2} \mathrm{O}_{2}$ treatment to improve $\mathrm{Pb}$ sorption, with an improvement of both the sorption kinetics and capacity. In the case of sewage sludge biochar, the sorption capacity was about 2-fold and 10-fold higher after $\mathrm{H}_{2} \mathrm{O}_{2}$ and $\mathrm{KOH}$ treatment, respectively. However, 
special attention should be paid to the washing procedure after chemical modification to avoid an inhibition of metal sorption due to a significant release of soluble compounds from an improperly washed modified biochar.

\section{Acknowledgements}

Patrice Fondanèche is acknowledged for technical assistance with the $\mathrm{Pb}$ measurement. This research project has received funding from the European Union's Horizon 2020 research and innovation programme under the Marie Sklodowska-Curie grant agreement $N^{\circ} 643071$.

\section{References}

Afnor, 1997a. Qualité de l'eau. Tome 2. Lignes directrices pour le dosage du carbone organique total (TOC) et carbone organique dissous (COD). Norme EN 1484, sixth ed. France.

Afnor, 1997b. Qualité de l'eau. Tome 3. Dosage du phosphore. Dosage spectrométrique à l'acide du molybdate d'ammonium. Norme EN 1189, sixth ed. France.

Afnor, 1996. Qualité de l'eau. Tome 2. Détermination de l'alcalinité. Norme EN ISO 9963-1, sixth ed. France.

Agrafioti, E., Kalderis, D., Diamadopoulos, E., 2014. Arsenic and chromium removal from water using biochars derived from rice husk, organic solid wastes and sewage sludge. J. Environ. Manage. 133, 309-314.

Al-Degs, Y.S., El-Barghouthi, M.I., Issa, A.A., Khraisheh, M.A., Walker, G.M., 2006. Sorption of $\mathrm{Zn}(\mathrm{II}), \mathrm{Pb}(\mathrm{II})$, and $\mathrm{Co}(\mathrm{II})$ using natural sorbents: Equilibrium and kinetic studies. Water Res. 40, 2645-2658.

Andrejkovicova, S., Sudagar, A., Rocha, J., Patinha, C., Hajjaji, W., Da Silva, E.F., Velosa, 
A., Rocha, F., 2016. The effect of natural zeolite on microstructure, mechanical and heavy metals adsorption properties of metakaolin based geopolymers. Appl. Clay Sci. $126,141-152$.

Bogusz, A., Nowak, K., Stefaniuk, M., Dobrowolski, R., Oleszczuk, P., 2017. Synthesis of biochar from residues after biogas production with respect to cadmium and nickel removal from wastewater. J. Environ. Manage. 201, 268-276.

Cechinel, M.A.P., Ulson De Souza, S.M.A.G., Ulson De Souza, A.A., 2014. Study of lead (II) adsorption onto activated carbon originating from cow bone. J. Clean. Prod. 65, $342-349$.

Chen, X., Chen, G., Chen, L., Chen, Y., Lehmann, J., McBride, M.B., Hay, A.G., 2011. Adsorption of copper and zinc by biochars produced from pyrolysis of hardwood and corn straw in aqueous solution. Bioresour. Technol. 102, 8877-8884.

EPA., US, 1996. Acid digestion of sediments, sludges, and soils, revision 2, 1-12.

Fan, S., Tang, J., Wang, Y., Li, H., Zhang, H., Tang, J., Wang, Z., Li, X., 2016. Biochar prepared from co-pyrolysis of municipal sewage sludge and tea waste for the adsorption of methylene blue from aqueous solutions: Kinetics, isotherm, thermodynamic and mechanism. J. Mol. Liq. 220, 432-441.

Ho, S.H., Chen, Y., Yang, Z., Nagarajan, D., Chang, J.S., Ren, N., 2017. High-efficiency removal of lead from wastewater by biochar derived from anaerobic digestion sludge. Bioresour. Technol. 246, 142-149.

Huang, H., Tang, J., Gao, K., He, R., Zhao, H., Werner, D., 2017. Characterization of KOH modified biochars from different pyrolysis temperatures and enhanced adsorption of antibiotics. RSC Adv. 7, 14640-14648.

Inyang, M., Gao, B., Yao, Y., Xue, Y., Zimmerman, A.R., Pullammanappallil, P., Cao, X., 2012. Removal of heavy metals from aqueous solution by biochars derived from 
anaerobically digested biomass. Bioresour. Technol. 110, 50-56.

Inyang, M.I., Gao, B., Yao, Y., Xue, Y., Zimmerman, A., Mosa, A., Pullammanappallil, P., Ok, Y.S., Cao, X., 2016. A review of biochar as a low-cost adsorbent for aqueous heavy metal removal. Crit. Rev. Environ. Sci. Technol. 4, 406-433.

Jiang, M., Wang, Q., Jin, X., Chen, Z., 2009. Removal of Pb(II) from aqueous solution using modified and unmodified kaolinite clay. J. Hazard. Mater. 170, 332-339.

Jin, H., Capareda, S., Chang, Z., Gao, J., Xu, Y., Zhang, J., 2014. Biochar pyrolytically produced from municipal solid wastes for aqueous $\mathrm{As}(\mathrm{V})$ removal: Adsorption property and its improvement with KOH activation. Bioresour. Technol. 169, 622-629.

Kaul, B., Sandhu, R.S., Depratt, C., Reyes, F., 1999. Follow-up screening of lead-poisoned children near an auto battery recycling plant, Haina, Dominican Republic. Environ. Health Perspect. 107, 917-920.

Li, H., Dong, X., da Silva, E.B., de Oliveira, L.M., Chen, Y., Ma, L.Q., 2017. Mechanisms of metal sorption by biochars: Biochar characteristics and modifications. Chemosphere $178,466-478$.

Li, J., Li, Y., Wu, Y., Zheng, M., 2014. A comparison of biochars from lignin, cellulose and wood as the sorbent to an aromatic pollutant. J. Hazard. Mater. 280, 450-457.

Lin, Y., Munroe, P., Joseph, S., Henderson, R., Ziolkowski, A., 2012. Water extractable organic carbon in untreated and chemical treated biochars. Chemosphere 87, 151-157.

Liou, T.H., Wu, S.J., 2009. Characteristics of microporous/mesoporous carbons prepared from rice husk under base- and acid-treated conditions. J. Hazard. Mater. 171, 693-703.

Liu, P., Liu, W.J., Jiang, H., Chen, J.J., Li, W.W., Yu, H.Q., 2012. Modification of bio-char derived from fast pyrolysis of biomass and its application in removal of tetracycline from aqueous solution. Bioresour. Technol. 121, 235-240.

Liu, Z., Zhang, F.S., 2009. Removal of lead from water using biochars prepared from 
hydrothermal liquefaction of biomass. J. Hazard. Mater. 167, 933-939.

Lu, H., Zhang, W., Yang, Y., Huang, X., Wang, S., Qiu, R., 2012. Relative distribution of $\mathrm{Pb}^{2+}$ sorption mechanisms by sludge-derived biochar. Water Res. 46, 854-862.

Mohan, D., Sarswat, A., Ok, Y.S., Pittman, C.U., 2014. Organic and inorganic contaminants removal from water with biochar, a renewable, low cost and sustainable adsorbent $-\mathrm{A}$ critical review. Bioresour. Technol. 160, 191-202.

Petrovic, J.T., Stojanovic, M.D., Milojkovic, J. V., Petrovic, M.S., Sostaric, T.D., Lausevic, M.D., Mihajlovic, M.L., 2016. Alkali modified hydrochar of grape pomace as a perspective adsorbent of $\mathrm{Pb}^{2+}$ from aqueous solution. J. Environ. Manage. 182, 292-300.

Pituello, C., Francioso, O., Simonetti, G., Pisi, A., Torreggiani, A., Berti, A., Morari, F., 2014. Characterization of chemical-physical, structural and morphological properties of biochars from biowastes produced at different temperatures. J. Soils Sediments 15, 792804.

Rajapaksha, A.U., Chen, S.S., Tsang, D.C.W., Zhang, M., Vithanage, M., Mandal, S., Gao, B., Bolan, N.S., Ok, Y.S., 2016. Engineered/designer biochar for contaminant removal/immobilization from soil and water: Potential and implication of biochar modification. Chemosphere 148, 276-291.

Regmi, P., Garcia Moscoso, J.L., Kumar, S., Cao, X., Mao, J., Schafran, G., 2012. Removal of copper and cadmium from aqueous solution using switchgrass biochar produced via hydrothermal carbonization process. J. Environ. Manage. 109, 61-69.

Saifullah, Dahlawi, S., Naeem, A., Rengel, Z., Naidu, R., 2018. Biochar application for the remediation of salt-affected soils: Challenges and opportunities. Sci. Total Environ. 625, $320-335$.

Sizmur, T., Fresno, T., Akgül, G., Frost, H., Moreno Jiménez, E., 2017. Biochar modification to enhance sorption of inorganics from water. Bioresour. Technol. 246, 34-47. 
Tóth, G., Hermann, T., Silva, M.R. Da, Montanarella, L., 2016. Heavy metals in agricultural soils of the European Union with implications for food safety. Environemtal Int. 88, 299-309.

Wang, S., Gao, B., Li, Y., Mosa, A., Zimmerman, A.R., Ma, L.Q., Harris, W.G., Migliaccio, K.W., 2015. Manganese oxide-modified biochars: Preparation, characterization, and sorption of arsenate and lead. Bioresour. Technol. 181, 13-17.

Wang, Y., Liu, R., 2018. $\mathrm{H}_{2} \mathrm{O}_{2}$ treatment enhanced the heavy metals removal by manure biochar in aqueous solutions. Sci. Total Environ. 628-629, 1139-1148.

Wu, W., Li, J., Lan, T., Müller, K., Khan, N., Chen, X., Xu, S., Zheng, L., Chu, Y., Li, J., Yuan, G., Wang, H., 2017. Unraveling sorption of lead in aqueous solutions by chemically modified biochar derived from coconut fiber: A microscopic and spectroscopic investigation. Sci. Total Environ. 576, 766-774.

Xue, Y., Gao, B., Yao, Y., Inyang, M., Zhang, M., Zimmerman, A.R., Ro, K.S., 2012. Hydrogen peroxide modification enhances the ability of biochar (hydrochar) produced from hydrothermal carbonization of peanut hull to remove aqueous heavy metals: Batch and column tests. Chem. Eng. J. 200-202, 673-680.

Zhang, F., Wang, X., Yin, D., Peng, B., Tan, C., Liu, Y., Tan, X., Wu, S., 2015. Efficiency and mechanisms of $\mathrm{Cd}$ removal from aqueous solution by biochar derived from water hyacinth (Eichornia crassipes). J. Environ. Manage. 153, 68-73.

Zhang, T., Zhu, X., Shi, L., Li, J., Li, S., Lu, J., Li, Y., 2017. Efficient removal of lead from solution by celery-derived biochars rich in alkaline minerals. Bioresour. Technol. 235, 185-192.

Zhang, W., Mao, S., Chen, H., Huang, L., Qiu, R., 2013. Pb(II) and Cr(VI) sorption by biochars pyrolyzed from the municipal wastewater sludge under different heating conditions. Bioresour. Technol. 147, 545-552. 
Zielińska, A., Oleszczuk, P., Charmas, B., Skubiszewska-Zięba, J., Pasieczna-Patkowska, S., 2015. Effect of sewage sludge properties on the biochar characteristic. J. Anal. Appl. Pyrolysis 112, 201-213. 


\section{Figures}

(a) $\mathrm{SS}-\mathrm{KOH}^{\text {sem }}$

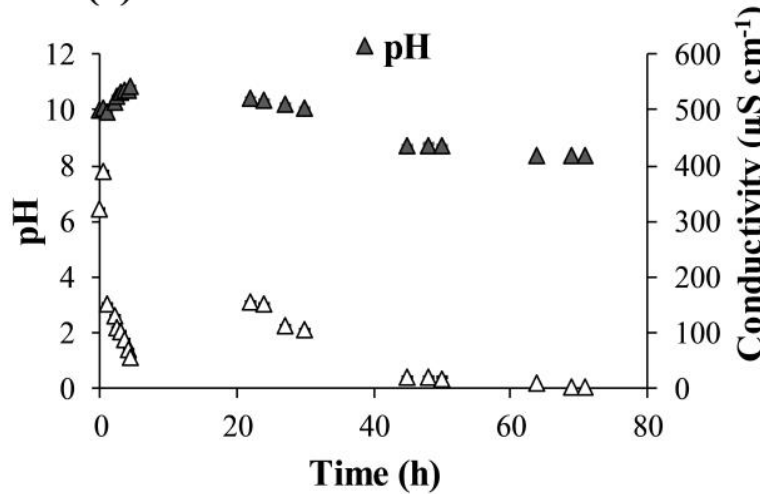

(b) $\mathrm{SS}-\mathrm{H}_{2} \mathrm{O}_{2}{ }^{\text {sem }}$

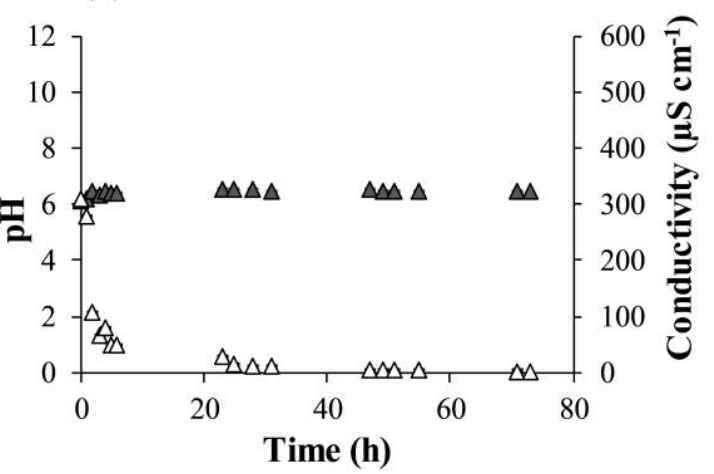

(c) $\mathrm{SS}-\mathrm{KOH}^{\mathrm{sem}}$

(d) $\mathrm{SS}-\mathrm{H}_{2} \mathrm{O}_{2}{ }^{\text {sem }}$
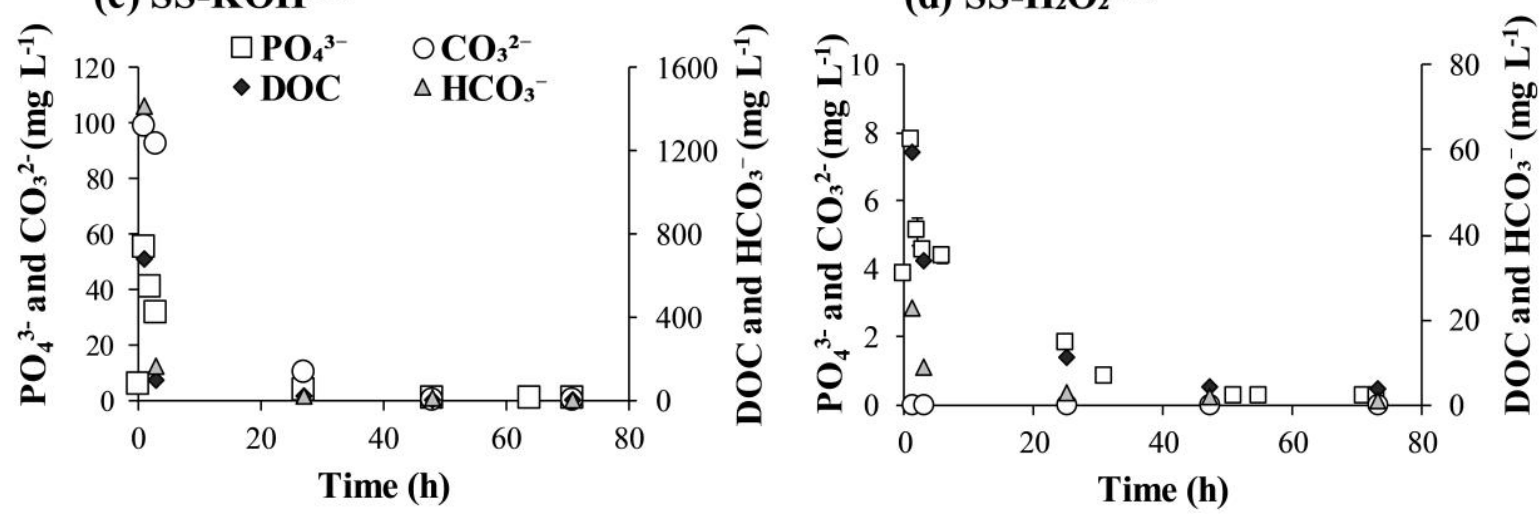

Fig. 1. Evolution of $\mathrm{pH}$ and conductivity during continuous washing of SS-KOH${ }^{\mathrm{sem}}$ (a) and SS- $\mathrm{H}_{2} \mathrm{O}_{2}{ }^{\mathrm{sem}}$ (b), and concentration profile of phosphate, (bi)carbonate and dissolved organic carbon (DOC) along continuous washing of SS-KOH${ }^{\mathrm{sem}}$ (c) and $\mathrm{SS}-\mathrm{H}_{2} \mathrm{O}_{2}{ }^{\mathrm{sem}}$ (d). 


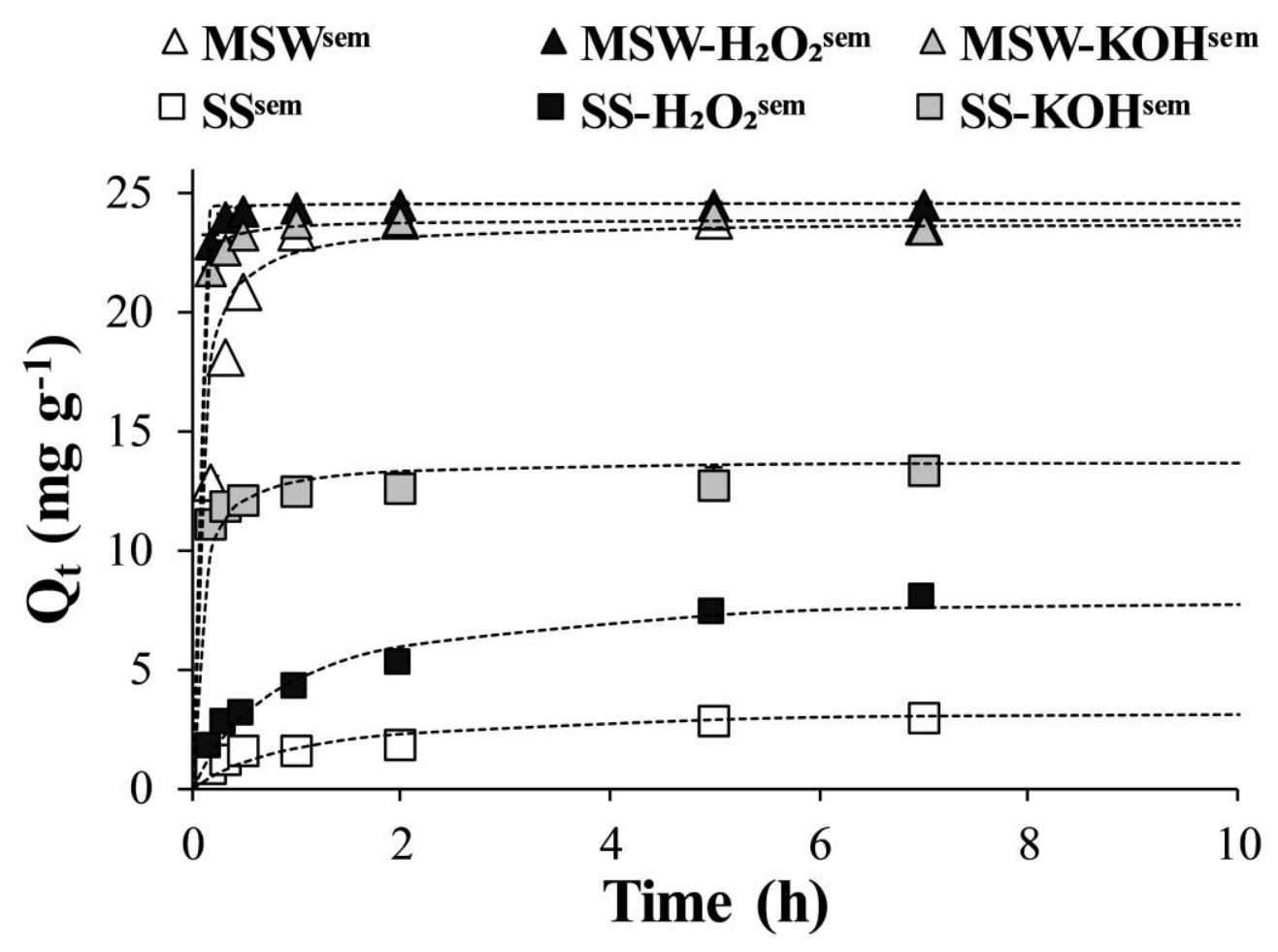

Fig. 2. Adsorption kinetics for $\mathrm{Pb}$ by semi-continuous washed $\mathrm{MSW}{ }^{\mathrm{sem}}, \mathrm{MSW}-\mathrm{H}_{2} \mathrm{O}_{2}{ }^{\mathrm{sem}}$, MSW-KOH ${ }^{\text {sem }}, \mathrm{SS}^{\mathrm{sem}}, \mathrm{SS}-\mathrm{H}_{2} \mathrm{O}_{2}{ }^{\mathrm{sem}}$ and $\mathrm{SS}-\mathrm{KOH}^{\mathrm{sem}}$ at different contact times at an initial solution $\mathrm{pH}$ of 5 and initial $\mathrm{Pb}$ concentration of $100 \mathrm{mg} \mathrm{L}^{-1}$ fitted with the pseudo-second order kinetic model. 

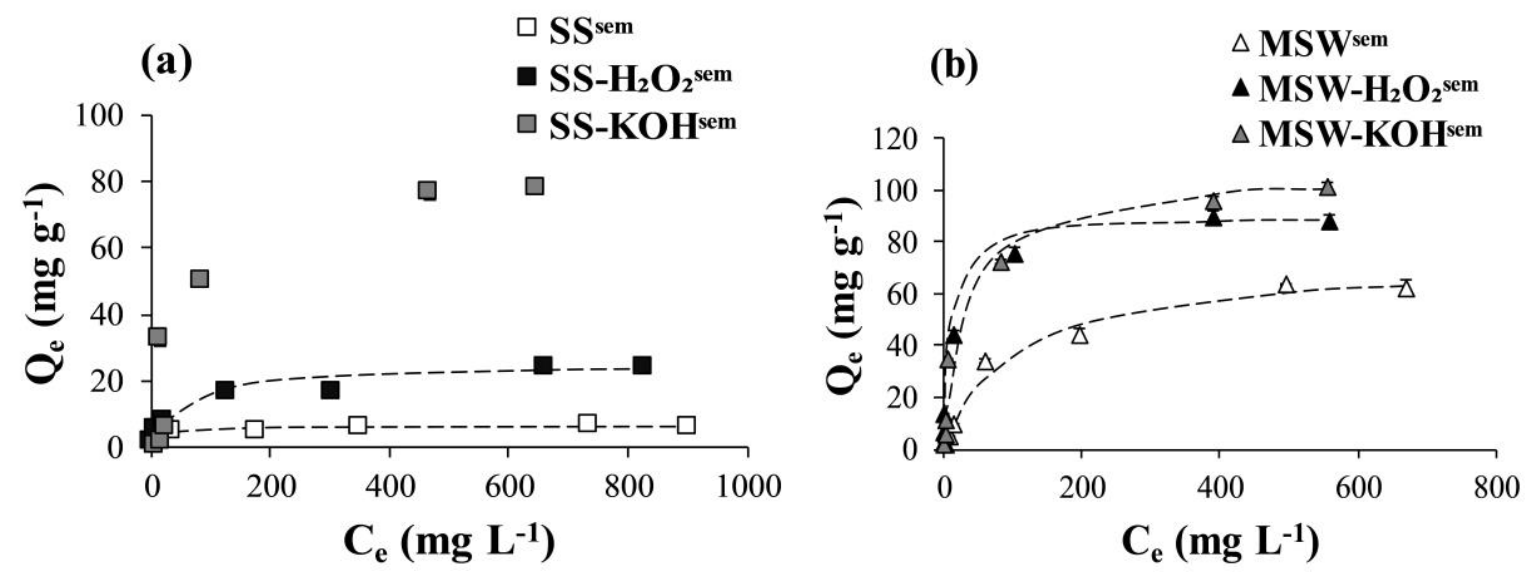

Fig. 3. Adsorption isotherms for $\mathrm{Pb}$ by semi-continuous washed $\mathrm{SS}^{\mathrm{sem}}, \mathrm{SS}-\mathrm{H}_{2} \mathrm{O}_{2}{ }^{\mathrm{sem}}$ and $\mathrm{SS}-$ $\mathrm{KOH}^{\text {sem }}$ (a) and by $\mathrm{MSW}^{\mathrm{sem}}, \mathrm{MSW}-\mathrm{H}_{2} \mathrm{O}_{2}{ }^{\text {sem }}$ and $\mathrm{MSW}-\mathrm{KOH}^{\text {sem }}$ (b) at different equilibrium $\mathrm{Pb}$ (II) concentrations at an initial solution $\mathrm{pH}$ of 5 fitted with the Langmuir model (except $\mathrm{SS}-\mathrm{KOH}^{\mathrm{sem}}$ due to non-fitting). 

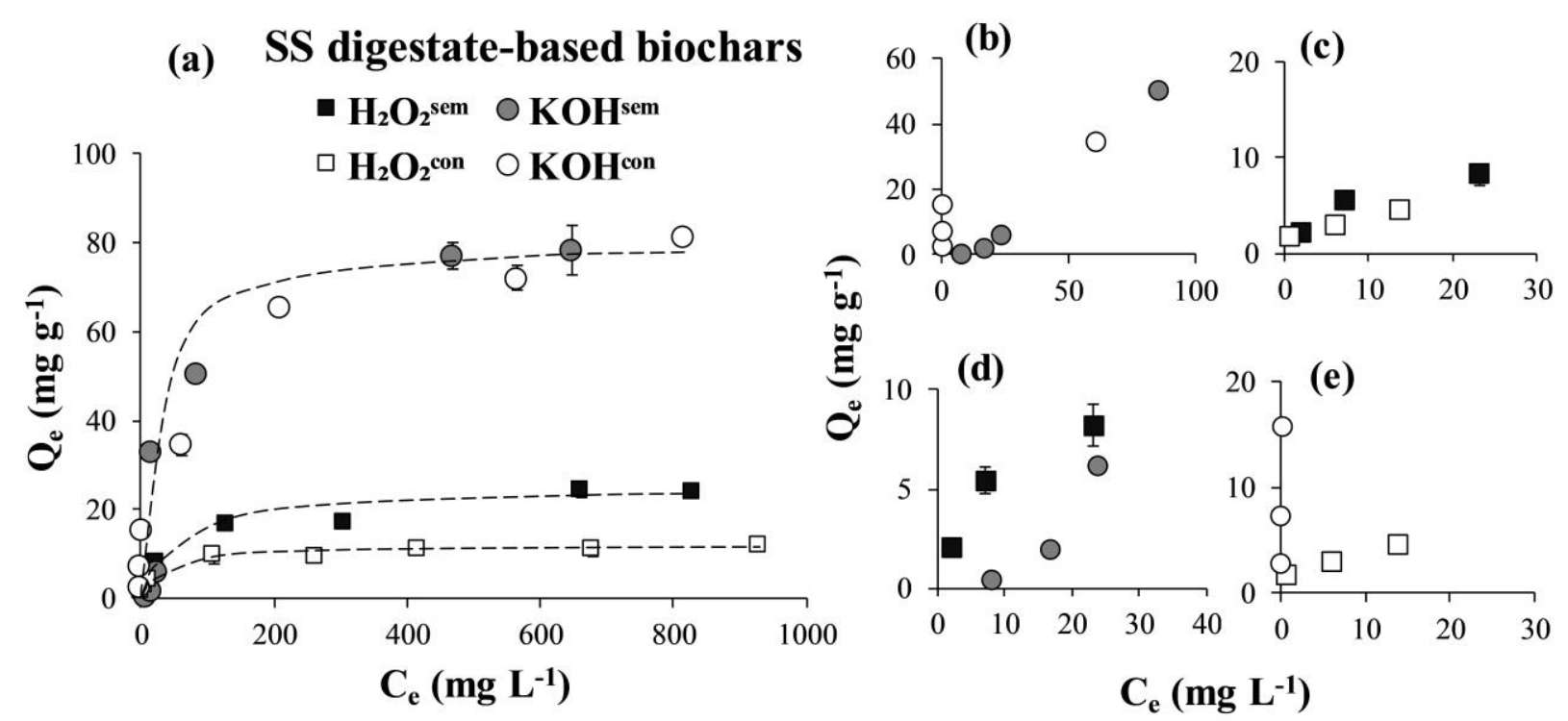

Fig. 4. Comparison of the $\mathrm{Pb}$ adsorption isotherms on sewage sludge digestate-based biochars with different washing modes fitted with the Langmuir model (except $\mathrm{KOH}^{\text {sem }}$ due to non-fitting) (a). Figure (b) to (e) are zooms of $C_{e}$ at low concentration ranges (< 100 mg $\mathrm{L}^{-1}$ ); semi-continuous washed $\mathrm{KOH}^{\text {sem }}$ versus continuous washed $\mathrm{KOH}^{\text {con }}$ (b), $\mathrm{H}_{2} \mathrm{O}_{2}{ }^{\text {sem }}$ versus $\mathrm{H}_{2} \mathrm{O}_{2}{ }^{\text {con }}$ (c), and with different chemical treatments; $\mathrm{KOH}^{\text {sem }}$ versus $\mathrm{H}_{2} \mathrm{O}_{2}{ }^{\text {sem }}$ (d), and $\mathrm{KOH}^{\text {con }}$ versus $\mathrm{H}_{2} \mathrm{O}_{2}{ }^{\text {con }}$ (e). 

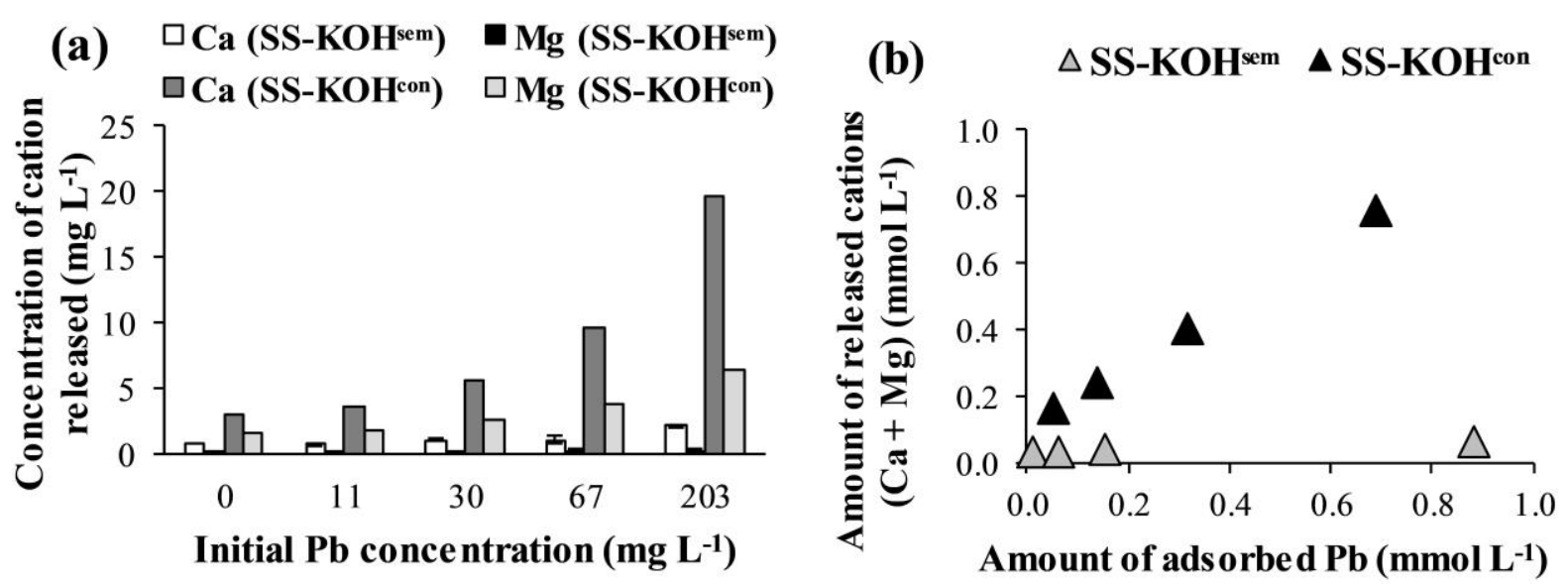

Fig. 5. Comparison of $\mathrm{Ca}^{2+}$ and $\mathrm{Mg}^{2+}$ released by SS-KOH${ }^{\mathrm{sem}}$ (semi-continuous washed) and SS-KOH${ }^{\text {con }}$ (continuous washed) (a), and the amount of adsorbed $\mathrm{Pb}$ versus the summation of the released cations $\left(\mathrm{Ca}^{2+}\right.$ and $\left.\mathrm{Mg}^{2+}\right)$ at $\mathrm{Pb}$ adsorption equilibrium (b). 


\section{Tables}

\section{Table 1}

The $\mathrm{pH}$ and concentrations of $\mathrm{Ca}, \mathrm{K}, \mathrm{Mg}, \mathrm{Na}, \mathrm{Al}, \mathrm{Fe}$ and $\mathrm{Mn}$ in the raw organic fraction of municipal solid waste digestate (RMSW), its derived biochar (MSW ${ }^{\mathrm{sem}}$ ) with semi-continuous washing, raw sewage sludge digestate (RSS) and its derived biochar (SS $\left.{ }^{\text {sem }}\right)$ with semi-continuous washing.

\begin{tabular}{lllllllll}
\hline Biochar & pH in & $\mathrm{Ca}$ & $\mathrm{K}$ & $\mathrm{Mg}$ & $\mathrm{Na}$ & $\mathrm{Al}$ & $\mathrm{Fe}$ & $\mathrm{Mn}$ \\
& water & $\left(\mathrm{g} \mathrm{kg}^{-1}\right)$ & $\left(\mathrm{g} \mathrm{kg}^{-1}\right)$ & $\left(\mathrm{g} \mathrm{kg}^{-1}\right)$ & $\left(\mathrm{g} \mathrm{kg}^{-1}\right)$ & $\left(\mathrm{g} \mathrm{kg}^{-1}\right)$ & $\left(\mathrm{g} \mathrm{kg}^{-1}\right)$ & $\left(\mathrm{mg} \mathrm{kg}^{-1}\right)$ \\
\hline RMSW & $8.0 \pm 0.1$ & $89.2 \pm 1.4$ & $32.1 \pm 0.3$ & $7.3 \pm 0.1$ & $32.2 \pm 0.2$ & $17.6 \pm 0.2$ & $11.4 \pm 0.1$ & $322.9 \pm 2.7$ \\
MSW $^{\text {sem }}$ & $8.9 \pm 0.1$ & $114.9 \pm 0.4$ & $21.8 \pm 0.2$ & $10.4 \pm 0.1$ & $31.9 \pm 0.2$ & $14.2 \pm 0.1$ & $16.1 \pm 0.2$ & $417.4 \pm 2.9$ \\
RSS & $6.0 \pm 0.1$ & $20.2 \pm 0.3$ & $3.6 \pm 0.9$ & $5.3 \pm 0.1$ & $4.2 \pm 0.5$ & $11.4 \pm 0.4$ & $66.0 \pm 0.8$ & $476.9 \pm 6.3$ \\
SS & $6.5 \pm 0.1$ & $29.5 \pm 0.4$ & $4.4 \pm 0.1$ & $8.0 \pm 0.1$ & $4.6 \pm 0.1$ & $14.3 \pm 0.2$ & $65.7 \pm 0.8$ & $769.9 \pm 8.0$ \\
\hline
\end{tabular}




\section{Table 2}

The $\mathrm{pH}$ and specific surface area of chemically-modified sewage sludge digestate biochar with semi-continuous washing $\left(\mathrm{SS}_{\mathrm{H}} \mathrm{H}_{2} \mathrm{O}_{2}{ }^{\text {sem }}\right.$ and SS-KOH $\left.{ }^{\text {sem }}\right)$ and with continuous washing $\left(\mathrm{SS}-\mathrm{H}_{2} \mathrm{O}_{2}{ }^{\mathrm{con}}\right.$ and $\left.\mathrm{SS}-\mathrm{KOH}^{\mathrm{con}}\right)$.

\begin{tabular}{lcc}
\hline Biochar & $\mathrm{pH}$ in water & $\mathrm{S}_{\mathrm{BET}}{ }^{\mathrm{a}}\left(\mathrm{m}^{2} \mathrm{~g}^{-1}\right)$ \\
\hline $\mathrm{SS}-\mathrm{H}_{2} \mathrm{O}_{2}{ }^{\text {sem }}$ & $6.2 \pm 0.1$ & $3.6 \pm 0.1$ \\
$\mathrm{SS}-\mathrm{KOH}^{\text {sem }}$ & $10.1 \pm 0.1$ & $3.0 \pm 0.1$ \\
$\mathrm{SS}^{\mathrm{H}} \mathrm{H}_{2} \mathrm{O}_{2}{ }^{\text {con }}$ & $6.5 \pm 0.1$ & $5.7 \pm 0.1$ \\
$\mathrm{SS}-\mathrm{KOH}^{\text {con }}$ & $8.4 \pm 0.1$ & $7.9 \pm 0.1$
\end{tabular}

${ }^{\mathrm{a}} \mathrm{S}_{\mathrm{BET}}$ refers to Brunauer-Emmett-Teller (BET) surface area of biochar. 
Table 3

Effect of biochar modification $\left(\mathrm{H}_{2} \mathrm{O}_{2}\right.$ and $\left.\mathrm{KOH}\right)$ and biochar washing (semi-continuous and continuous) on the $\mathrm{Pb}$ adsorption capacity.

\begin{tabular}{|c|c|c|c|c|c|c|}
\hline \multirow{2}{*}{ Biochar } & \multicolumn{3}{|c|}{ Langmuir isotherm model } & \multicolumn{3}{|c|}{ Freundlich isotherm model } \\
\hline & $Q_{m}{ }^{\mathrm{a}}$ & $K_{L}^{\mathrm{b}}$ & $R^{2}$ & $K_{F}^{\mathrm{c}}$ & $n$ & $R^{2}$ \\
\hline $\mathrm{MSW}^{\mathrm{sem}}$ & 72.9 & 0.010 & 0.992 & 1.430 & 1.584 & 0.940 \\
\hline $\mathrm{MSW}-\mathrm{H}_{2} \mathrm{O}_{2}{ }^{\mathrm{sem}}$ & 90.0 & 0.109 & 0.999 & 9.895 & 2.624 & 0.894 \\
\hline MSW-KOH ${ }^{\mathrm{sem}}$ & 106.3 & 0.030 & 0.997 & 4.908 & 1.888 & 0.860 \\
\hline $\mathrm{SS}^{\mathrm{sem}}$ & 6.5 & 0.069 & 0.994 & 2.136 & 5.646 & 0.782 \\
\hline $\mathrm{SS}-\mathrm{H}_{2} \mathrm{O}_{2}{ }^{\mathrm{sem}}$ & 25.1 & 0.018 & 0.984 & 2.117 & 2.633 & 0.955 \\
\hline $\mathrm{SS}-\mathrm{KOH}^{\mathrm{sem}}$ & 151.5 & 0.001 & 0.293 & 1.201 & 1.472 & 0.566 \\
\hline $\mathrm{SS}-\mathrm{H}_{2} \mathrm{O}_{2}{ }^{\text {con }}$ & 12.0 & 0.034 & 0.993 & 1.952 & 3.527 & 0.967 \\
\hline $\mathrm{SS}-\mathrm{KOH}^{\mathrm{con}}$ & 80.6 & 0.037 & 0.987 & 12.406 & 3.462 & 0.926 \\
\hline
\end{tabular}




\section{Supplementary Information}

\section{Lead sorption by biochar produced from digestates:}

\section{Consequences of chemical modification and washing}

Suchanya Wongrod ${ }^{\mathrm{a}, \mathrm{b}, \mathrm{c}}$, Stéphane Simon ${ }^{\mathrm{c}}$, Gilles Guibaud ${ }^{\mathrm{c}, *}$, Piet N.L. Lens $^{\mathrm{b}}$, Yoan Pechaud ${ }^{\mathrm{a}}$, David Huguenot ${ }^{\mathrm{a}}$, Eric D. van Hullebusch ${ }^{\mathrm{a}, \mathrm{b}}$

\footnotetext{
${ }^{a}$ Université Paris-Est, Laboratoire Géomatériaux et Environnement (EA 4508), UPEM, 77454, Marne-la-Vallée, France

${ }^{\mathrm{b}}$ IHE Delft Institute for Water Education, P.O. Box 3015, 2601 DA Delft, The Netherlands

${ }^{\text {c } U n i v e r s i t e ́ ~ d e ~ L i m o g e s, ~ P E I R E N E-G r o u p e m e n t ~ d e ~ R e c h e r c h e ~ E a u ~ S o l ~ E n v i r o n n e m e n t ~(E A ~ 7500), ~ F a c u l t e ́ ~ d e s ~}$ Sciences et Techniques, 123 avenue Albert Thomas, 87060 Limoges, France
}

*Corresponding author: gilles.guibaud@unilim.fr 


\section{XRD and FTIR analysis}

X-ray diffractometry (XRD) was employed to identify the crystalline structures presented in raw and modified biochars. The samples were grounded to less than $100 \mu \mathrm{m}$ particle size and were characterized using a powder diffractometer (AXS D8, Bruker, Germany) with $\mathrm{Cu} \mathrm{K} \alpha$ radiation at $1.54 \AA$ wavelength, over the $2 \theta$ range from $10^{\circ}$ to $32^{\circ}$, for 10 seconds per step, at $40 \mathrm{kV}$ voltage and $40 \mathrm{~mA}$ current with a Solx ( $\mathrm{Si}-\mathrm{Li}$ ) detector. The crystalline compounds present in biochar were identified by search-match software with reference from the American Mineralogist Crystal Structure Database.

Fourier transform infrared spectroscopy (FTIR) were recorded to identify the functional groups present on biochar surfaces. Each sample was mixed with $\mathrm{KBr}$ in a ratio of $1 \mathrm{mg}$ sample (particle size $100 \mu \mathrm{m}$ ) per $200 \mathrm{mg} \mathrm{KBr}$ and the pellet was prepared by compression under vacuum (Jouraiphy et al., 2005). The analysis was performed using a Shimadzu IRAffinity-1 Spectrometer with a deuterated-triglycine sulfate (DTGS) detector. The number of scans was 12 with a resolution of $16 \mathrm{~cm}^{-1}$ and a frequency in a range from 4000 to $800 \mathrm{~cm}^{-1}$. 
XRD spectra of biochars
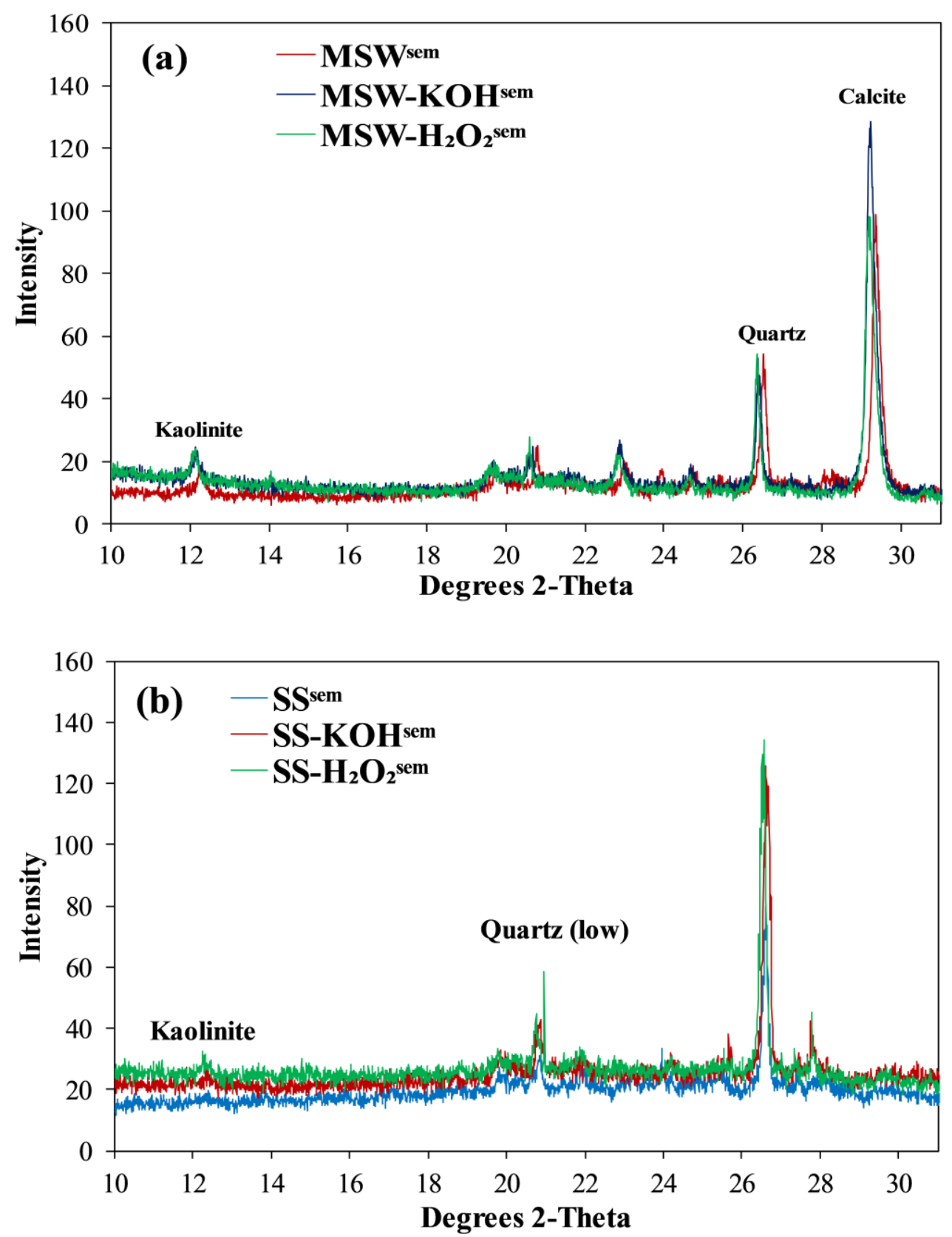

Fig. S1. XRD spectra of semi-continuous washed $\mathrm{MSW}^{\mathrm{sem}}, \mathrm{MSW}-\mathrm{KOH}^{\mathrm{sem}}$ and MSW$\mathrm{H}_{2} \mathrm{O}_{2}{ }^{\mathrm{sem}}$ (a) and SS ${ }^{\mathrm{sem}}, \mathrm{SS}-\mathrm{KOH}^{\mathrm{sem}}$ and SS- $\mathrm{H}_{2} \mathrm{O}_{2}{ }^{\mathrm{sem}}(\mathrm{b})$.

XRD analysis showed that $\mathrm{MSW}^{\mathrm{sem}}$ contained the crystalline structures of kaolinite $\left(\mathrm{Al}_{2} \mathrm{Si}_{2} \mathrm{O}_{5}(\mathrm{OH})_{4}\right)$, quartz $\left(\mathrm{SiO}_{2}\right)$ and calcite $\left(\mathrm{CaCO}_{3}\right)$ at $2 \theta 12.38^{\circ}, 26.68^{\circ}$ and $29.51^{\circ}$, 
respectively (Fig. S1(a)). Similar trends were also found in its chemically-modified biochar with slight shifts on the XRD spectra. For instance, the XRD peak of $\mathrm{CaCO}_{3}$ was shifted from $29.36^{\circ}\left(\mathrm{MSW}^{\mathrm{sem}}\right)$ to $29.23^{\circ}\left(\mathrm{MSW}-\mathrm{KOH}^{\mathrm{sem}}\right)$ and $29.20^{\circ}\left(\mathrm{MSW}-\mathrm{H}_{2} \mathrm{O}_{2}{ }^{\mathrm{sem}}\right)$. On the other hand, only $\mathrm{Al}_{2} \mathrm{Si}_{2} \mathrm{O}_{5}(\mathrm{OH})_{4}$ and $\mathrm{SiO}_{2}$ were detected in $\mathrm{SS}^{\mathrm{sem}}$, SS-KOH${ }^{\text {sem }}$ and $\mathrm{SS}^{-\mathrm{H}_{2} \mathrm{O}_{2}}{ }^{\text {sem }}$ (Fig. S1(b)). The results showed no significant differences of XRD spectra between the raw and chemical treated sewage sludge biochars. Kaolinite and carbonates present in the biochar can be partly involved in adsorption of $\mathrm{Pb}$ onto the biochar surface. 


\section{FTIR spectra of biochars}
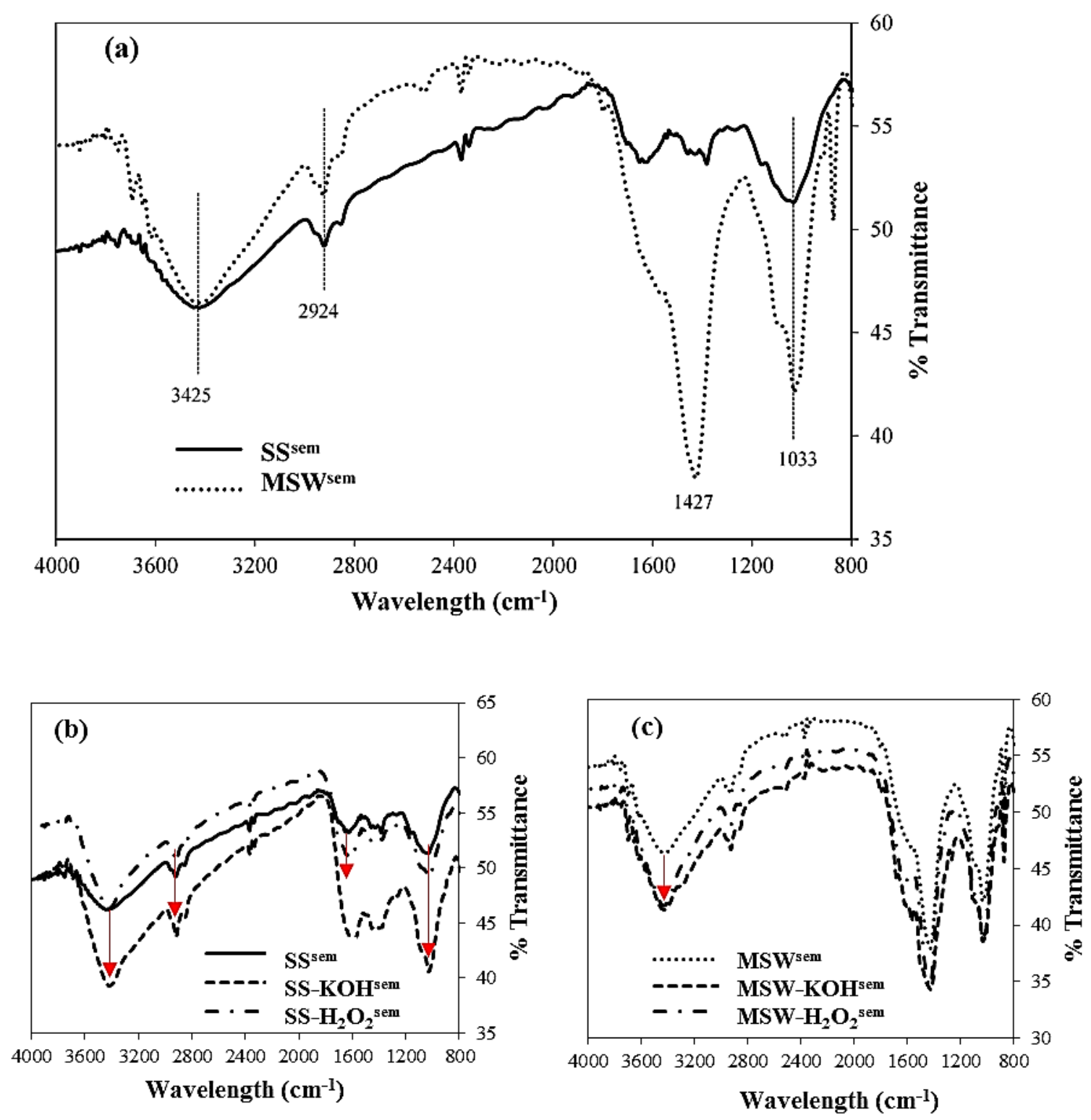

Fig. S2. Comparison of the FTIR spectra of semi-continuous washed $\mathrm{SS}^{\mathrm{sem}}$ and $\mathrm{MSW}^{\mathrm{sem}}$ (a), $\mathrm{SS}^{\mathrm{sem}}, \mathrm{SS}-\mathrm{KOH}^{\mathrm{sem}}, \mathrm{SS}-\mathrm{H}_{2} \mathrm{O}_{2}{ }^{\mathrm{sem}}(\mathrm{b})$, and $\mathrm{MSW}^{\mathrm{sem}}, \mathrm{MSW}^{-\mathrm{KOH}^{\mathrm{sem}}}$ and MSW- $\mathrm{H}_{2} \mathrm{O}_{2}{ }^{\mathrm{sem}}$ (c).

The peak band of $3425 \mathrm{~cm}^{-1}$ referred to the stretching vibration of $\mathrm{O}-\mathrm{H}$ functional groups (H-bonded) of alcohols and phenols and was present in all biochars (Fig. S2(a)). The bands at $2924 \mathrm{~cm}^{-1}$ was due to the vibration of $\mathrm{C}-\mathrm{H}$ stretching of long chain aliphatic groups (Chen et al., 2011) and was also found in all biochars (Fig. S2(a)). The bands of 1660-1600 
$\mathrm{cm}^{-1}$ were assigned to the stretching vibrations of $\mathrm{C}=\mathrm{C}$ and were observed only in $\mathrm{SS}^{\mathrm{sem}}, \mathrm{SS}$ $\mathrm{KOH}^{\text {sem }}$ and SS-H $\mathrm{O}_{2}{ }^{\text {sem }}$ (Fig. S2(b)). Since sewage sludge digestate is generally composed of cellulose, hemicellulose and lignin (Jouraiphy et al., 2005), thus the spectra of the amides band are broad bands of $1690-1640 \mathrm{~cm}^{-1}$. The broad bands between $1442-1384 \mathrm{~cm}^{-1}$ was assigned to $-\mathrm{CH}_{2}$ scissoring and were observed in raw and modified biochars from sewage sludge (Fig. S2(b)). A strong intensity of $-\mathrm{CH}_{2}$ scissoring was found at a peak of $1427 \mathrm{~cm}^{-1}$ in $\mathrm{MSW}^{\mathrm{sem}}, \mathrm{MSW}-\mathrm{KOH}^{\mathrm{sem}}$ and $\mathrm{MSW}-\mathrm{H}_{2} \mathrm{O}_{2}{ }^{\text {sem }}$ (Fig. S2(c)). The stretching of carboxylate groups and $\mathrm{C}-\mathrm{O}$ of alcohols appeared in the sample between 1300 and $1000 \mathrm{~cm}^{-1}$. The peaks at $1033 \mathrm{~cm}^{-1}$ were assigned to $\mathrm{C}-\mathrm{C}$ skeleton vibration and $\mathrm{C}-\mathrm{O}$ stretching vibration and were found in all biochars (Fig. S2(a, b, c)). The FTIR spectra provide the qualitative information of functional groups present on the surfaces of biochars. The results demonstrated the differences in surface functional groups between $\mathrm{MSW}^{\mathrm{sem}}$ and $\mathrm{SS}^{\mathrm{sem}}$ corresponding to different feedstock type and pyrolysis temperature. From Fig. S2(b), it is obvious that there were similar FTIR spectra between $\mathrm{SS}^{\mathrm{sem}}, \mathrm{SS}-\mathrm{KOH}^{\mathrm{sem}}, \mathrm{SS}-\mathrm{H}_{2} \mathrm{O}_{2}{ }^{\text {sem }}$ with a small shift at 1635 $\mathrm{cm}^{-1}\left(\mathrm{SS}^{\mathrm{sem}}\right)$ to $1597 \mathrm{~cm}^{-1}\left(\mathrm{SS}-\mathrm{KOH}^{\mathrm{sem}}\right)$. 


\section{Adsorption kinetics}

The simulation of the sorption kinetics for $\mathrm{Pb}(\mathrm{II})$ by raw and modified biochars was performed using pseudo-first-order (Eq. 1) and pseudo-second-order (Eq. 2) kinetic models, which are illustrated as followed:

$$
\begin{aligned}
& \log \left(Q_{e}-Q_{t}\right)=\log Q_{e}-\frac{k_{1} t}{2.303} \\
& \frac{t}{Q_{t}}=\frac{1}{k_{2} Q_{e}^{2}}+\frac{t}{Q_{e}}
\end{aligned}
$$

where $Q_{t}$ and $Q_{e}$ are $\mathrm{Pb}(\mathrm{II})$ adsorption capacity $\left(\mathrm{mg} \mathrm{g}^{-1}\right)$ at time $t(\mathrm{~h})$ and equilibrium, $k_{l}$ $\left(\mathrm{h}^{-1}\right)$ and $k_{2}\left(\mathrm{~g}(\mathrm{mg} \mathrm{h})^{-1}\right)$ are the rate constants for pseudo-first-order and pseudo-secondorder models, respectively (Liu \& Zhang, 2009). The pseudo-first-order curves were plotted via $\log \left(Q_{e}-Q_{t}\right)$ versus time $\mathrm{t}$ in which the values of $k_{1}$ can be obtained from the slope corresponding to Eq. (1). The pseudo-second-order model was also applied to test the experimental data from the plot of $t / Q_{t}$ against $t$, from which $Q_{e}$ and $k_{2}$ values can be calculated from the slope and interception of this plot, respectively.

\section{Adsorption isotherms}

Langmuir and Freundlich models are presented in equation (3) and (4), respectively:

$$
\begin{aligned}
& \frac{C_{e}}{Q_{e}}=\frac{1}{K_{L} Q_{m}}+\frac{C_{e}}{Q_{m}} \\
& \ln Q_{e}=\ln K_{F}+\frac{1}{n} \ln C_{e}
\end{aligned}
$$

where $C_{e}$ is the equilibrium $\mathrm{Pb}$ solution concentration $\left(\mathrm{mg} \mathrm{L}^{-1}\right), Q_{e}$ and $Q_{m}$ are the $\mathrm{Pb}(\mathrm{II})$ adsorption capacity at equilibrium and at maximum capacity $\left(\mathrm{mg} \mathrm{g}^{-1}\right), n$ is the Freundlich constant which indicates the favorability of adsorption, and $K_{L}$ and $K_{F}$ are the adsorption constants for the Langmuir and Freundlich isotherm models, respectively. 
(a) $\quad \square$ Initial pH (after sorption) $\quad \square$ Final pH (24 h)

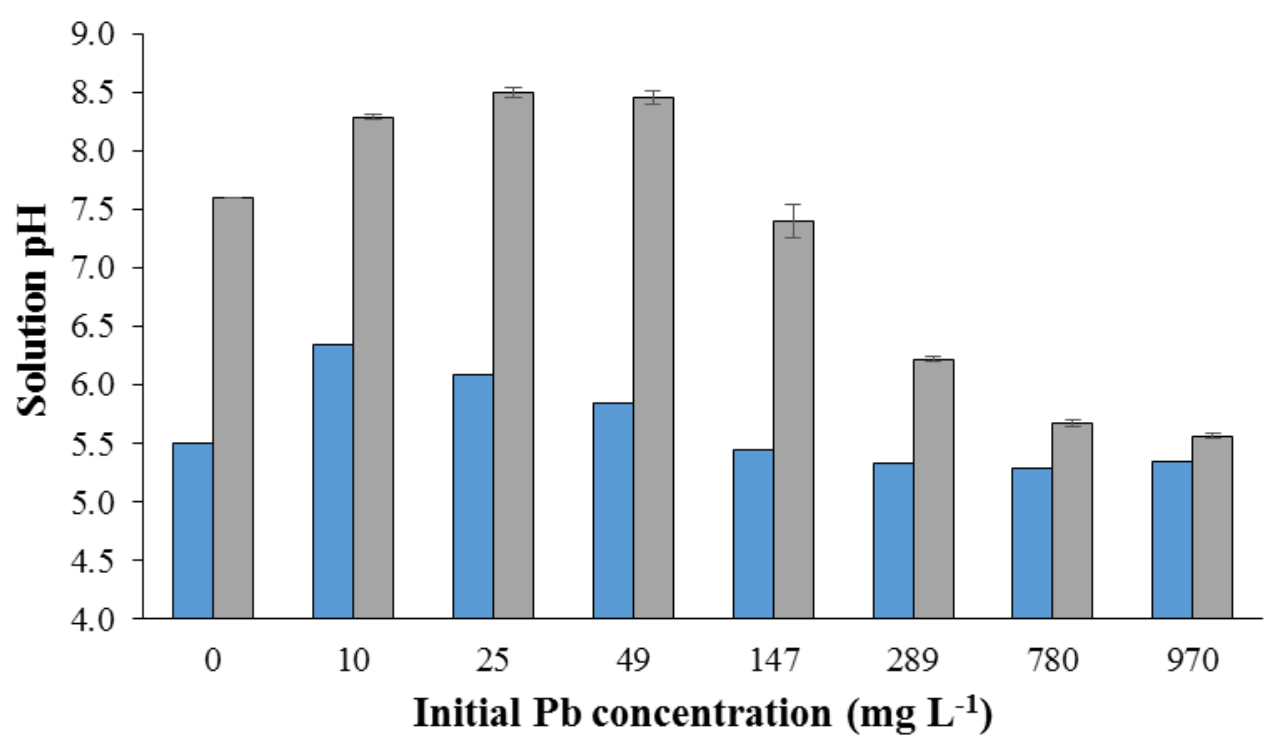

(b)

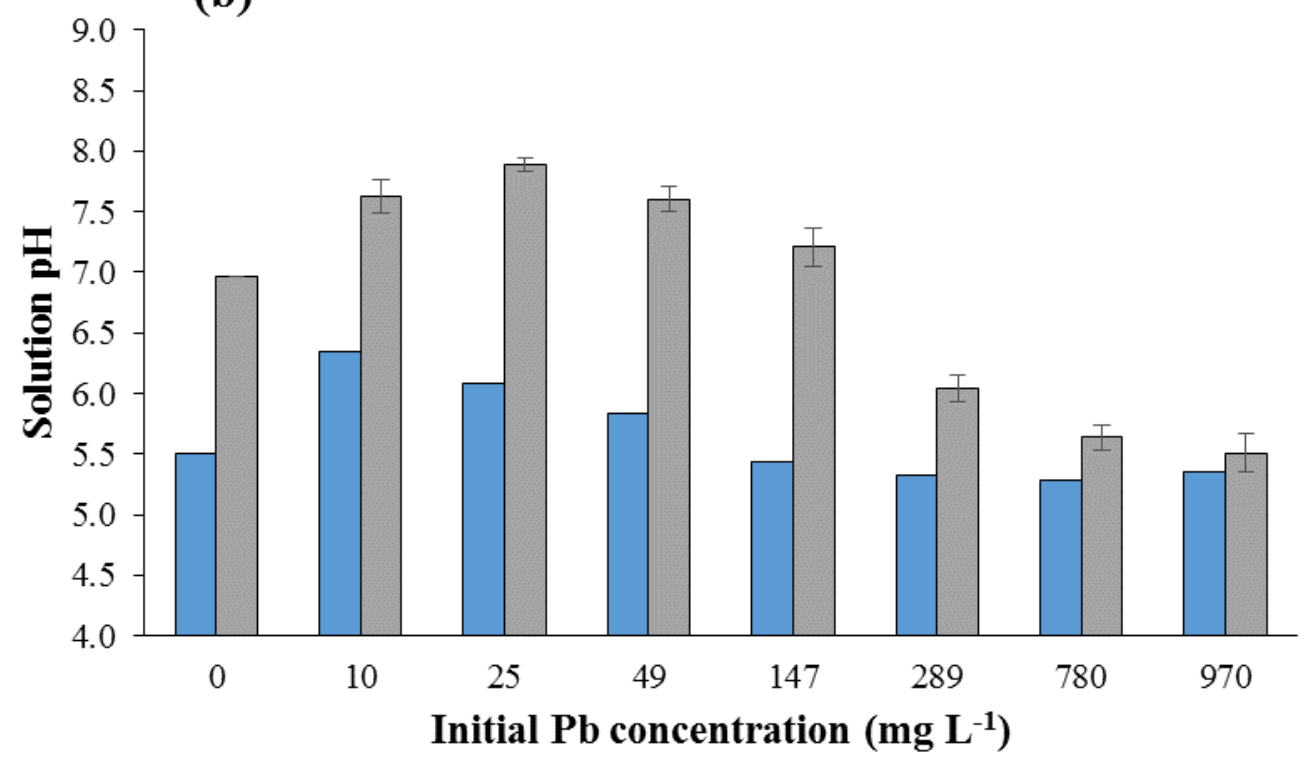

Fig. S3. The evolution of solution $\mathrm{pH}$ during $\mathrm{Pb}$ adsorption isotherms onto $\mathrm{SS}-\mathrm{KOH}^{\mathrm{sem}}$ (a) and MSW-KOH ${ }^{\text {sem }}$ 
Table S1.

Comparison of maximum adsorption capacities for lead by biochar produced from different waste materials.

\begin{tabular}{|c|c|c|c|c|c|}
\hline Biochar material & $\begin{array}{l}\text { Pyrolysis } \\
\text { temperature }\end{array}$ & $Q_{m}\left(\mathrm{mg} \mathrm{g}^{-1}\right)$ & Isotherm well-fitted model & $\begin{array}{l}\text { Expriemental conditions: } \\
\text { initial } \mathrm{pH} \text {, biochar dosage }\end{array}$ & Reference \\
\hline Peanut shell & 350 & 52.8 & Freundlich, Langmuir & $\mathrm{pH} \mathrm{5,4 \textrm {g } \mathrm { L } ^ { - 1 }}$ & Wang et al. (2015) \\
\hline Medicine material residues & 350 & 46.1 & Langmuir & $\mathrm{pH} 5,4 \mathrm{~g} \mathrm{~L}^{-1}$ & Wang et al. (2015) \\
\hline Pine wood & 300 & 3.9 & Langmuir & $\mathrm{pH} 5,4 \mathrm{~g} \mathrm{~L}^{-1}$ & Liu \& Zhang (2009) \\
\hline Rice husk & 300 & 1.8 & Langmuir & $\mathrm{pH} 5,4 \mathrm{~g} \mathrm{~L}^{-1}$ & Liu \& Zhang (2009) \\
\hline Digested dairy waste & 600 & 51.4 & - & $2 \mathrm{~g} \mathrm{~L}^{-1}$ & Inyang et al. (2012) \\
\hline Digested whole sugar beet & 600 & 40.8 & Langmuir & $2 \mathrm{~g} \mathrm{~L}^{-1}$ & Inyang et al. (2012) \\
\hline Sewage sludge digestate & 350 & 6.5 & Langmuir & $\mathrm{pH} \mathrm{5,} 4 \mathrm{~g} \mathrm{~L}^{-1}$ & This study \\
\hline Organic fraction of municipal solid & 400 & 72.9 & Langmuir & $\mathrm{pH} \mathrm{5,} 4 \mathrm{~g} \mathrm{~L}^{-1}$ & This study \\
\hline waste digestate & & & & & \\
\hline
\end{tabular}




\section{Table S2.}

Chemical characteristics of the organic fraction of municipal solid waste digestate (RMSW), its derived biochar (MSW ${ }^{\text {sem }}$ ), sewage sludge digestate (RSS) and its derived biochar $\left(\mathbf{S S}^{\text {sem }}\right)$.

\begin{tabular}{lrrrr}
\hline Parameters & RMSW & MSW $^{\text {sem }}$ & RSS & SS $^{\text {sem }}$ \\
\hline Biochar yield (\%wt) & $\mathrm{NA}^{\mathrm{a}}$ & $74 \pm 1$ & $\mathrm{NA}$ & NA \\
Ash (\%wt) & $52 \pm 1$ & $68 \pm 1$ & $\mathrm{NA}$ & $\mathrm{NA}$ \\
Moisture content (\%wt) & $81 \pm 1$ & $\mathrm{NA}$ & $\mathrm{NA}$ & $\mathrm{NA}$ \\
$\mathrm{As}\left(\mathrm{mg} \mathrm{kg}^{-1}\right)^{\mathrm{b}}$ & $\mathrm{dl}$ & $\mathrm{dl}$ & $79 \pm 3^{\mathrm{d}}$ & $34 \pm 12$ \\
$\mathrm{Cd}\left(\mathrm{mg} \mathrm{kg}^{-1}\right)$ & $\mathrm{dl}$ & $\mathrm{dl}$ & $\mathrm{dl}$ & $9 \pm 1$ \\
$\mathrm{Cr}\left(\mathrm{mg} \mathrm{kg}^{-1}\right)$ & $94 \pm 1$ & $100 \pm 2$ & $42 \pm 1$ & $48 \pm 1$ \\
$\mathrm{Cu}\left(\mathrm{mg} \mathrm{kg}^{-1}\right)$ & $261 \pm 7$ & $436 \pm 5$ & $390 \pm 10$ & $617 \pm 7$ \\
$\mathrm{Ni}\left(\mathrm{mg} \mathrm{kg}^{-1}\right)$ & $43 \pm 5$ & $38 \pm 3$ & $25 \pm 1$ & $41 \pm 1$ \\
$\mathrm{~Pb}\left(\mathrm{mg} \mathrm{kg}^{-1}\right)$ & $101 \pm 5$ & $130 \pm 12$ & $80 \pm 9$ & $85 \pm 3$ \\
$\mathrm{Zn}\left(\mathrm{mg} \mathrm{kg}^{-1}\right)$ & $693 \pm 13$ & $888 \pm 12$ & $756 \pm 10$ & $1017 \pm 13$
\end{tabular}

${ }^{\mathrm{a}} \mathrm{NA}$ refers to not available.

${ }^{\mathrm{b}}$ Values reported on dry basis.

${ }^{\mathrm{c}} \mathrm{dl}$ refers to below detection limit.

${ }^{\mathrm{d}}$ Values reported as means $(\mathrm{n}=3)$ followed by standard deviation.

Table S2 shows the metal(loid) contents of RMSW, MSW ${ }^{\text {sem }}$, RSS and SS ${ }^{\text {sem }}$. Metals such as $\mathrm{Cr}, \mathrm{Cu}, \mathrm{Pb}$ and $\mathrm{Zn}$ were retained in the biochars during pyrolysis, while $\mathrm{As}$ (metalloid) was volatilized at the temperature below $400{ }^{\circ} \mathrm{C}$ (Table S2), this was also affirmed by previous studies from Duan et al. (2017). As expected, $\mathrm{Cu}$ and $\mathrm{Zn}$ were the main components in both the solid digestates and biochars (Table S2), which was in correlation to the studies from Pituello et al. (2014). Additionally, no metals exceeded the limit values of metal(loid)s present in the sludge based on the French guidelines (Directive 86/278/EEC). 
Table S3.

Parameters of pseudo-first-order and pseudo-second-order kinetics for lead sorption by $\mathrm{SS}^{\mathrm{sem}}, \mathrm{SS}^{-\mathrm{H}_{2} \mathrm{O}_{2}{ }^{\mathrm{sem}}, \mathrm{SS}-\mathrm{KOH}^{\mathrm{sem}}, \mathrm{MSW}^{\mathrm{sem}}, \mathrm{MSW}-\mathrm{H}_{2} \mathrm{O}_{2}{ }^{\mathrm{sem}} \text { and MSW-KOH }}{ }^{\mathrm{sem}}$.

\begin{tabular}{|c|c|c|c|c|c|c|c|}
\hline \multirow{2}{*}{ Sample } & \multirow[b]{2}{*}{$Q_{e, \exp }$} & \multicolumn{3}{|c|}{ Pseudo-first-order (PFO) } & \multicolumn{3}{|c|}{ Pseudo-second-order (PSO) } \\
\hline & & $Q_{e}$ & $k_{l}$ & $R^{2}$ & $Q_{e}$ & $k_{2}$ & $R^{2}$ \\
\hline $\mathrm{SS}^{\mathrm{sem}}$ & 3.4 & 3.5 & 0.536 & 0.146 & 3.5 & 0.270 & 0.997 \\
\hline $\mathrm{SS}-\mathrm{H}_{2} \mathrm{O}_{2}{ }^{\mathrm{sem}}$ & 8.2 & 8.8 & 0.633 & 0.653 & 8.5 & 0.137 & 0.999 \\
\hline $\mathrm{SS}-\mathrm{KOH}^{\mathrm{sem}}$ & 13.7 & 13.9 & 1.780 & $\mathrm{NF}^{\mathrm{a}}$ & 14.0 & 1.057 & 0.999 \\
\hline $\mathrm{MSW}^{\mathrm{sem}}$ & 23.7 & 24.2 & 4.287 & 0.990 & 23.8 & 0.735 & 0.999 \\
\hline $\mathrm{MSW}-\mathrm{H}_{2} \mathrm{O}_{2}{ }^{\mathrm{sem}}$ & 24.4 & 24.5 & 10.177 & 0.856 & 24.5 & 18.496 & 1.000 \\
\hline MSW-KOH ${ }^{\text {sem }}$ & 23.8 & 24.0 & 7.766 & 0.78 & 23.8 & 3.528 & 1.000 \\
\hline
\end{tabular}

${ }^{a} \mathrm{NF}$ refers to no satisfactory fit by the model. 


\section{References}

Chen, X., Chen, G., Chen, L., Chen, Y., Lehmann, J., McBride, M.B., Hay, A.G., 2011. Adsorption of copper and zinc by biochars produced from pyrolysis of hardwood and corn straw in aqueous solution. Bioresour. Technol. 102, 8877-8884.

Duan, L., Li, X., Jiang, Y., Lei, M., Dong, Z., Longhurst, P., 2017. Arsenic transformation behaviour during thermal decomposition of $P$. vittata, an arsenic hyperaccumulator. J. Anal. Appl. Pyrolysis 124, 584-591.

Inyang, M., Gao, B., Yao, Y., Xue, Y., Zimmerman, A.R., Pullammanappallil, P., Cao, X., 2012. Removal of heavy metals from aqueous solution by biochars derived from anaerobically digested biomass. Bioresour. Technol. 110, 50-56.

Jouraiphy, A., Amir, S., El Gharous, M., Revel, J.C., Hafidi, M., 2005. Chemical and spectroscopic analysis of organic matter transformation during composting of sewage sludge and green plant waste. Int. Biodeterior. Biodegrad. 56, 101-108.

Liu, Z., Zhang, F.S., 2009. Removal of lead from water using biochars prepared from hydrothermal liquefaction of biomass. J. Hazard. Mater. 167, 933-939.

Pituello, C., Francioso, O., Simonetti, G., Pisi, A., Torreggiani, A., Berti, A., Morari, F., 2014. Characterization of chemical-physical, structural and morphological properties of biochars from biowastes produced at different temperatures. J. Soils Sediments 15, 792-804.

Wang, Z., Liu, G., Zheng, H., Li, F., Ngo, H.H., Guo, W., Liu, C., Chen, L., Xing, B., 2015. Investigating the mechanisms of biochar's removal of lead from solution. Bioresour. Technol. 177, 308-317. 